\title{
Lottery-like preferences and the MAX effect in the cryptocurrency market
}

\author{
Melisa Ozdamar ${ }^{*}$, Levent Akdeniz and Ahmet Sensoy
}

${ }^{*}$ Correspondence:

melisa.yilmaz@bilkent.edu.tr

Faculty of Business

Administration, Bilkent

University, 06800 Cankaya,

Ankara, Turkey

Data and materials are available upon request from the corresponding author. Ahmet Sensoy gratefully acknowledges support from the Turkish Academy of Sciences - Outstanding Young Scientists Award Program (TUBA-GEBIP).

\begin{abstract}
We investigate the significance of extreme positive returns in the cross-sectional pricing of cryptocurrencies. Through portfolio-level analyses and weekly cross-sectional regressions on all cryptocurrencies in our sample period, we provide evidence for a positive and statistically significant relationship between the maximum daily return within the previous month (MAX) and the expected returns on cryptocurrencies. In particular, the univariate portfolio analysis shows that weekly average raw and riskadjusted return differences between portfolios of cryptocurrencies with the highest and lowest MAX deciles are $3.03 \%$ and $1.99 \%$, respectively. The results are robust with respect to the differences in size, price, momentum, short-term reversal, liquidity, volatility, skewness, and investor sentiment.
\end{abstract}

Keywords: Cryptocurrencies, MAX effect, Lottery-like preference, Cross-sectional predictability

JEL Classification: G11, G12, G17

\section{Introduction}

With the invention of Bitcoin (Nakamoto 2008) followed by altcoins, the skeptical yet unstoppable rise of the cryptocurrency market has drawn significant attention in recent years. This unique financial market provides many key features to be explored. One of these features is the effect of maximum daily return (MAX) on cryptocurrency prices. In their seminal paper, Bali et al. (2011) introduce the MAX effect showing that stocks with extreme historical positive returns are inclined to exhibit lower returns in the future. This effect in asset pricing has received empirical support by many studies in the stock market literature, including Fong and Toh (2014), Barinov (2018), and Hung and Yang (2018). In this study, following Bali et al. (2011), we investigate the role of lagged extreme positive returns in the cross-sectional pricing of cryptocurrencies. ${ }^{1}$

Recently, the cryptocurrency market has attracted increased attention from investors as it offered a brand new and distinguished investment opportunity. ${ }^{2}$ Unlike other

\footnotetext{
${ }_{1}^{1}$ The literature on MAX effect and lottery-like preferences can be further tied to the collective opinion dynamics of investors in financial markets. For more information on this subject, see Zha et al. (2021).

2 As a subgroup of new Fintech innovations, cryptocurrencies have been attracting attention to the greatest extent in recent years. For more information on other novel Fintech approaches, see Kou et al. (2021a) and the references therein.
} author(s) and the source, provide a link to the Creative Commons licence, and indicate if changes were made. The images or other third party material in this article are included in the article's Creative Commons licence, unless indicated otherwise in a credit line to the material. If material is not included in the article's Creative Commons licence and your intended use is not permitted by statutory regulation or exceeds the permitted use, you will need to obtain permission directly from the copyright holder. To view a copy of this licence, visit http:// creativecommons.org/licenses/by/4.0/. 
financial assets, cryptocurrencies are based on electronic cash payment systems without any participation of higher authority or physical representation. It provides online trading through an algorithm that helps trace transactions. This attractive financial asset has an infinite divisibility with low transaction costs. The literature has indicated certain features of the cryptocurrency market, such as price clustering (Urquhart 2017), diversification benefits (Corbet et al. 2018a; Kajtazi and Moro 2019; Urquhart and Zhang 2019; Akhtaruzzaman et al. 2020), pricing bubbles (Corbet et al. 2018b), volatility dynamics (Katsiampa et al. 2019; Shen et al. 2020; Akyildirim et al. 2020), and arbitrage opportunities (Makarov and Schoar 2020).

A group of recent studies investigate the predictability of cryptocurrencies, that is, the inefficiency in this market. However, the results are somewhat contradictory. ${ }^{3}$ For example, Caporale et al. (2018) examines the return persistence-and therefore predictability-of the cryptocurrency market and shows a positive correlation between past and future returns of four main cryptocurrencies. Similarly, Zhang et al. (2018) and Al-Yahyaee et al. (2018) report inefficiency in the cryptocurrency market, and Tzouvanas et al. (2019) shows that momentum effect exists in the short-term. Akyildirim et al. (2021) finds evidence that the cryptocurrency market is inefficient even in the weak form as it is possible to predict future returns by applying machine learning tools on historical prices. ${ }^{4}$ Contrariwise, Vidal-Tomas and Ibanez (2018) and Sensoy (2019) argue that the efficiency of Bitcoin has evolved over time. Focusing on momentum effects in cryptocurrencies, Grobys and Sapkota (2019) indicates a slight efficiency in the cryptocurrency market. Wei (2018) shows that as market liquidity increases, return predictability diminishes. However, the study reports signs of efficiency improvement only for Bitcoin while other cryptocurrencies remain inefficient.

As stated above, the predictability of cryptocurrency returns has been studied in detail by many researchers in the recent years. However, there is room to explore this concept, especially with respect to different dimensions, such as investor preferences. For example, empirical literature provides evidence that investors exhibit preference for lotterylike assets. Kumar (2009) documents the likelihood of individual investors to choose assets with a relatively low probability of a large payoff. The author defines these assets as low-priced with high idiosyncratic volatility and high idiosyncratic skewness. Following this argument, Bali et al. (2011) investigate the investor preference over lottery-like stocks using MAX as a proxy for extreme returns. In addition, they argue that regarding the tendency to extreme positive returns, these under-diversified investors show preference for skewness. Moreover, Fong and Toh (2014) uncover the dependency of MAX effect on investor sentiment and show that certain groups of institutional investors are also prone to gamble in high MAX stocks. Previous studies have shown that, in addition to the US equity market, European (Annaert et al. 2013; Walkshäusl 2014), Australian (Zhong and Gray 2016), Hong Kong (Chan and Chui 2016), Chinese (Nartea et al. 2017), and Brazilian (Berggrun et al. 2019) stock markets demonstrate the presence of the MAX effect.

\footnotetext{
${ }^{3}$ Refer to Corbet et al. (2019) for an excellent review on the literature of cryptocurrency markets.

${ }^{4}$ While this study uses a direct approach in feature selection, further advancements could be applied by choosing the model features in two stages. For an example, see Kou et al. (2021b).
} 
Motivated by these different lines of literature, we investigate whether and how the MAX effect exists in the cryptocurrency market. Following Bali et al. (2011), we start by sorting cryptocurrencies according to their maximum daily return in the past month. We examine weekly returns on the resulting portfolios for the period between January 2014 and September 2020. ${ }^{5}$ The average difference between weekly returns on the highest and lowest value-weighted MAX portfolios is found to be $3.03 \%$, whereas the difference in corresponding three-factor alphas is $1.99 \%$, both being significant with the Newey and West (1987) adjusted t-stat of 4.10 and 3.72, respectively. The results are robust to sorting cryptocurrencies each week based on averages of two, three, four, and five highest daily returns within the past month. This suggests that portfolios with the highest past extreme returns outperform portfolios with the lowest past extreme returns in the future. In addition to the documented investor preference over lottery-like assets, a positive difference between high MAX and low MAX portfolios indicates a permanent impact of extreme positive returns. For further examination, we perform bivariate portfolio analysis on raw returns and compare three-factor alphas, controlling for various characteristics, such as size, price, momentum, short-term reversal, and illiquidity. The bivariate analysis differs from the univariate analysis by double sort where we first categorize coins according to a certain characteristic and then sort by MAX to detect the MAX effect cleared from any other potential impact. The bivariate portfolio analysis and Fama and MacBeth (1973) cross-sectional regressions provide supporting evidence for the MAX effect. The univariate regression of MAX on lagged MAX, as well as the multivariate regression with seven additional control variables, produces positive, considerably large, and extremely significant MAX coefficient.

We contribute to the cryptocurrency literature by investigating the relationship between maximum daily returns and expected future returns. Coin-level cross-sectional regressions show that the MAX effect has an explanatory power over future cryptocurrency returns. Our results contradict with the findings of Grobys and Sapkota (2019), Jia et al. (2020), and Grobys and Junttila (2021). Grobys and Sapkota (2019) report no supporting evidence of momentum effects by testing 143 cryptocurrencies and indicate that the cryptocurrency market is not as inefficient as earlier studies suggest. Moreover, Jia et al. (2020) examine the predictive power of higher moments on the cross-section of expected returns using 84 cryptocurrencies. They document a significant return predictability of higher moments and a negative significant relationship between positive extreme returns and future returns. Similarly, Grobys and Junttila (2021) investigate the speculative behavior in the cryptocurrency market by utilizing a data set of 20 coins excluding Bitcoin for the period between January 2016 and December 2019. They report that investors tend to prefer cryptocurrencies with high payoffs and low subsequent returns. However, we note that these studies have limited samples, and we believe that the sample size is crucial for obtaining accurate results. Therefore, in this analysis, we use all cryptocurrencies over $\$ 5$ million market capitalization with publicly available data. This gives us 17 cryptocurrencies at the beginning of our sample period, which reaches up to 523 cryptocurrencies in the end. Our sample is very close to the entire

\footnotetext{
${ }^{5}$ We consider weekly returns as in the cryptocurrency market, trading and investor reactions to market sentiment is faster than the traditional financial markets (Dyhrberg 2016; Hong 2017).
} 
universe of cryptocurrencies traded in the market, which enhances the robustness of our findings. ${ }^{6}$ Furthermore, the conclusion of Li et al. (2020a) is consistent with our results that cryptocurrencies with the highest extreme returns pursue their superior performance in the future.

In this study, we additionally analyze the volatility effect on subsequent cryptocurrency returns. Ang et al. (2006) report that there exists a negative relationship between idiosyncratic volatility and expected returns, whereas Zhang and Li (2020) argue a contrary positive relation for cryptocurrencies. We find a high correlation between idiosyncratic volatility and maximum daily returns and suspect whether MAX acts as a substitute for volatility, which would make this effect transient in the cryptocurrency market. We examine this problem by performing bivariate portfolio analysis on MAX, wherein the sorting on the volatility component is performed by using both Garman and Klass (1980) volatility (VOL) and idiosyncratic volatility (IVOL) for robustness. Precisely, we first sort portfolios based on maximum daily returns, controlling for VOL (IVOL), and report a value-weighted average raw difference between high MAX and low MAX portfolios of $1.58 \%$ (0.91\%) with a t-stat of 5.17 (2.72). The high significance of returns indicate that MAX effect is valid and persistent. Furthermore, when we sort portfolios according to IVOL, controlling for MAX, we obtain insignificant differences for raw return and alpha differences between the highest and lowest idiosyncratic volatility deciles. We further conduct a cross-sectional regression analysis and find supporting evidence for a significant MAX effect and an insignificant volatility effect over expected returns. Consequently, the positive explanatory power of MAX on subsequent returns is robust to controls for various volatility measures.

Moreover, we examine the relationship between extreme positive returns and skewness. Empirical findings document that more positively skewed portfolios yield subsequent lower returns (Harvey and Siddique 2000; Smith 2007; Mitton and Vorkink 2007; Conrad et al. 2013). However, Brunnermeier and Gollier (2007) and Barberis and Huang (2008) theoretically show that this result is more likely to be reasoning from the overoptimism for low-price and low-probability states in which extreme returns are overweighted. Studies on cryptocurrencies present conflicting results on the impact of skewness on the cross-section of returns (Balcilar et al. 2017; Wei 2018). In addition, Jia et al. (2020) indicate that return predictability of skewness is affected by extreme positive returns. Therefore, we further analyze the relationship between MAX and skewness to test whether extreme positive returns proxy for skewness. We use two different measures, total skewness (TSKEW) and idiosyncratic skewness (ISKEW) (Boyer et al. 2010), and conduct bivariate portfolio analyses, along with cryptocurrency-level crosssectional return regressions. Our findings demonstrate that the MAX effect is robust when we control for total and idiosyncratic skewness.

Finally, we investigate the impact of investor sentiment on maximum daily returns as many studies in the empirical literature show that investor sentiment has an effect on cross-sectional returns (Baker and Wurgler 2006, 2007; Da et al. 2015; He et al. 2019).

\footnotetext{
${ }^{6} 2000$ cryptocurrencies narrow down to 973 in total, when we apply $\$ 5$ million market cap filter to exclude illiquid cryptocurrencies and obtain more reliable and robust results. However, when we conduct the same analyses using all of 2000 coins, the outcomes are similar to those presented in the study. Results are available upon request.
} 
Specifically, Stambaugh et al. (2012) document that overpricing of stocks is more prevalent during high sentiment periods. Fong and Toh (2014) demonstrate the dependence of MAX effect over investor sentiment and report that-controlling for the past sentiment-the significance of MAX effect decreases. Regarding the crytocurrency market, Karalevicius et al. (2018) report that investors are inclined to overreact to news on media; thus, Bitcoin prices act according to the sentiment direction. In addition, Polasik et al. (2015) indicate that Bitcoin returns are contingent upon popularity, media sentiment, and the total number of transactions. To investigate the speculative bubbles with relatively high returns in the cryptocurrency market, Chen and Hafner (2019) utilize StockTwits sentiment analysis and report high volatility during low sentiment periods. Considering the sentiment impact reported in the literature, we conduct a bivariate portfolio analysis, controlling for the investor sentiment. We observe that the difference between high MAX and low MAX value-weighted portfolio raw returns equals $2.80 \%$ (3.25\%) with a Newey-West adjusted t-stat of 3.16 (1.98) during the low (high) sentiment period. Furthermore, we plot the time-series of cumulative long-short portfolio returns and investor sentiment. In line with the findings of Fong and Toh (2014), in the cryptocurrency market, we report that the performance of long-short hedge portfolio based on MAX is higher following high sentiment periods. Our results support the momentum impact of extreme positive returns. Nevertheless, the MAX effect continues to be robust after controlling for the investor sentiment as it remains significant in both high and low sentiment states.

The remainder of the paper is organized as follows. Second section presents univariate and bivariate portfolio-level analyses and coin-level cross-sectional regressions. Third section discusses the relationship between extreme returns and volatility measures, while fourth and fifth sections focus on the connection of extreme returns with skewness and investor sentiment, respectively. Finally, sixth section concludes the paper.

\section{Maximum daily return and the cross-section of expected returns}

We use daily closing prices of all cryptocurrencies with publicly available data. ${ }^{7}$ We exclude cryptocurrencies with market capitalization below $\$ 5$ million, and we incorporate a new coin into the sample after waiting for six months. ${ }^{8}$ The data source is CoinMarketCap (https://coinmarketcap.com/coins/), and our sample spans the period from the beginning of January 2014 to the end of September 2020. Sample size starts with only 17 cryptocurrencies at the beginning and reaches up to 523 cryptocurrencies by the end of the period under examination.

\footnotetext{
7 List of cryptocurrencies are available upon request.

8 We thank the anonymous referee for this suggestion. Cryptocurrencies with low market capitalization show extreme low liquidity, which complicates the application of practical trading strategies in reasonable sizes. Moreover, when a coin is initially launched, price behavior might be very strange until it is adopted by users, miners, and traders. It takes some time for it to gain substantial acceptance and liquidity. Therefore, we consider cryptocurrencies with market caps over $\$ 5$ million and exclude the first six months of price behavior out of our sample.
} 


\section{Variable construction}

We construct most of our variables following Bali et al. (2011). Our variable of interest is the maximum daily return within the past month $(M A X)$, calculated weekly for each coin, as described in Eq. (1).

$$
\operatorname{MAX}_{i, t}=\max \left(R_{i, d}\right), \quad d=1, \ldots, D_{m}
$$

where $\mathrm{R}_{i, d}$ is the return on cryptocurrency $i$ on day $d$, and $D_{m}$ is the number of trading days in month m. ${ }^{9}$ To estimate BETA, we follow Scholes and Williams (1977) and Dimson (1979) and consider lag, current, and lead returns on market index. We estimate Eq. (2) weekly for each coin using daily returns within a month.

$$
\begin{aligned}
\mathrm{R}_{i, d}-r_{f, d}= & \alpha_{i}+\beta_{1, i}\left(R_{m, d-1}-r_{f, d-1}\right)+\beta_{2, i}\left(R_{m, d}-r_{f, d}\right) \\
& +\beta_{3, i}\left(R_{m, d+1}-r_{f, d+1}\right)+\epsilon_{i, d}
\end{aligned}
$$

where $\mathrm{R}_{m, d}$ is the cryptocurrency market portfolio return on day $d$, and $\mathrm{r}_{f, d}$ is the riskfree rate on day $d .{ }^{10}$ We measure $S I Z E$ by the natural logarithm of the cryptocurrency's market capitalization by the end of previous week. As another size variable, we measure PRICE by the natural logarithm of one plus the cryptocurrency's price by the end of previous week. The momentum variable $(M O M)$ is calculated weekly for each coin as the cumulative return over the previous three weeks starting two weeks ago, that is, the cumulative return from week $\mathrm{t}-4$ to week $\mathrm{t}-2$. Short-term reversal $(R E V)$ is defined as the cumulative return on cryptocurrency $i$ within the past week, that is, the cumulative return in week t-1. To measure illiquidity (ILLIQ), we follow Amihud (2002) and calculate the ratio of absolute daily cryptocurrency return to its mean dollar trading volume each week, as shown in Eq. (3).

$$
\operatorname{ILLIQ}_{i, t}=\frac{1}{D} \sum_{d=1}^{D} \frac{\left|R_{i, d}\right|}{V O L D_{i, d}}
$$

where $\operatorname{VOLD}_{i, d}$ is the respective trading volume in dollars and $\mathrm{D}$ is the total number of trading days in a week. Our final variable of interest is volatility $(V O L)$. To estimate weekly volatility of each coin, we follow Garman and Klass (1980) and use Eq. (4).

$$
\mathrm{VOL}_{i, t}=\sqrt{\frac{N}{D} \sum_{d=1}^{N}\left[\frac{1}{2}\left(\log \frac{H_{i, d}}{L_{i, d}}\right)^{2}-(2 \log (2)-1)\left(\log \frac{C_{i, d}}{O_{i, d}}\right)^{2}\right]}
$$

where $N$ is the total number of trading days in a month and $D$ is the total number of trading days in a week. $H_{i, d}, L_{i, d}, C_{i, d}$ and $O_{i, d}$ are the highest, lowest, closing, and opening price of cryptocurrency $i$, respectively, on day $d .^{11}$

\footnotetext{
${ }^{9}$ The meaning of trading days in the cryptocurrency market is different from that in the traditional stock market, as the coin market is always active. In our analysis, we assume a week and a month to be 7 and 28 trading days, respectively.

10 We construct a daily value-weighted cryptocurrency market index using all sample cryptocurrencies. Risk-free rate is the one-month T-bill return.

11 There exists a high cross-correlation between MAX and idiosyncratic volatility, which causes multicollinearity in the regression models. Therefore, we use Garman-Klass volatility (then the correlation coefficient between MAX and volatility becomes 0.0028 ) to capture the intraday information, which seems to have a considerable impact on price variability (Eross et al. 2019; Mensi et al. 2019; Jia et al. 2020).
} 
Table 1 Descriptive statistics of the main variables

\begin{tabular}{lcclllcc}
\hline & Mean & Median & SD & Skewness & Kurtosis & 25th Quartile & 75th Quartile \\
\hline MAX & 0.22 & 0.16 & 0.20 & 2.92 & 16.51 & 0.10 & 0.26 \\
BETA & 0.86 & 0.93 & 0.71 & -0.70 & 19.87 & 0.51 & 1.21 \\
SIZE & 17.12 & 16.72 & 1.44 & 1.07 & 3.51 & 15.99 & 17.90 \\
PRICE & 0.55 & 0.12 & 0.91 & 2.31 & 8.60 & 0.02 & 0.67 \\
MOM & 0.07 & 0.00 & 0.43 & 4.18 & 42.77 & -0.16 & 0.19 \\
REV & 0.02 & 0.00 & 0.20 & 2.37 & 23.23 & -0.09 & 0.09 \\
ILLIQ & 0.00 & 0.00 & 0.00 & 6.12 & 57.71 & 0.00 & 0.00 \\
VOL & 0.91 & 0.77 & 0.50 & 1.25 & 4.44 & 0.55 & 1.14 \\
\hline
\end{tabular}

Table reports summary statistics of the main variables used in the study. Mean, median, standard deviation, skewness, kurtosis, 25th and 75th quartiles of weekly calculations are shown. MAX refers to the maximum daily return within a month BETA is the market beta calculated as the sum of coefficients on lag, current and lead returns on market portfolio. SIZE equals the natural logarithm of the cryptocurrency's market capitalization by the end of previous week. PRICE is the natural logarithm of one plus the cryptocurrency's price. MOM stands for momentum that equals the cumulative return over the previous three weeks skipping past week. REV stands for short-term reversal and equals the return in the past week. ILLIQ refers to Amihud illiquidity measure, which is calculated by the ratio of absolute daily cryptocurrency return to its mean dollar trading volume. VOL refers to Garman-Klass volatility measure, which takes into account the highest, lowest, opening and closing prices

Table 1 shows descriptive statistics of variables. Our main variable of interest, MAX, has a mean value of $22 \%$ with a lower median value of $16 \%$. In addition, MOM, REV, and VOL averages are $7 \%, 2 \%$, and $91 \%$, respectively. Mean and median values of ILLIQ is slightly low, which indicates that we have been able to remove the most illiquid coins out of the sample.

\section{Univariate portfolio analysis}

We form decile portfolios by sorting cryptocurrencies based on MAX values and present the value-weighted and equal-weighted average weekly returns in Table 2. Portfolio 1 (10) is the portfolio of cryptocurrencies with the lowest (highest) maximum daily returns during the previous month. The first column of Table 2 shows that the valueweighted average raw return difference between decile 10 (high MAX) and decile 1 (low MAX) is $3.03 \%$ per week with a corresponding Newey-West adjusted t-stat of 4.10. Similarly, as shown the third column of Table 2, the raw difference between the low MAX and high MAX equal-weighted portfolio returns average $2.45 \%$ per week with a t-statistic of 3.22. Table 2 also reports the intercept terms (alphas) from regressions of the value-weighted and equal-weighted portfolio returns on a constant, the excess market return, a size factor, and a momentum factor, following Fama and French (1993) and Carhart (1997). The excess cryptocurrency market return is the difference between cryptocurrency market index return and the risk-free rate. For the size factor, we follow Liu et al. (2020) and Zhang and Li (2020) and split cryptocurrencies per week into three groups by market capitalization. We form value-weighted portfolios for each size group and calculate the difference between average returns of small and big size portfolios. Similarly, for the momentum factor, we split cryptocurrencies per week into three groups by momentum. ${ }^{12}$ We construct value-weighted portfolios for each momentum group, and we calculate the difference between average returns of the highest and lowest

\footnotetext{
${ }^{12}$ We compute momentum as the cumulative return over the past three weeks following Liu et al. (2020).
} 
Table 2 Returns and alphas on portfolios of cryptocurrencies sorted by MAX

\begin{tabular}{|c|c|c|c|c|c|}
\hline \multirow[t]{2}{*}{ Decile } & \multicolumn{2}{|l|}{ VW portfolios } & \multicolumn{2}{|l|}{ EW portfolios } & \multirow[b]{2}{*}{ Average MAX } \\
\hline & Average Return & Alpha & Average Return & Alpha & \\
\hline Low MAX & -0.009 & -0.009 & 0.006 & 0.003 & 0.056 \\
\hline 2 & -0.007 & -0.008 & 0.016 & 0.016 & 0.083 \\
\hline 3 & -0.007 & -0.008 & 0.012 & 0.013 & 0.099 \\
\hline 4 & -0.007 & -0.008 & 0.013 & 0.011 & 0.126 \\
\hline 5 & 0.002 & 0.001 & 0.024 & 0.021 & 0.132 \\
\hline 6 & 0.000 & 0.000 & 0.016 & 0.015 & 0.169 \\
\hline 7 & 0.010 & 0.008 & 0.017 & 0.013 & 0.200 \\
\hline 8 & 0.007 & 0.007 & 0.027 & 0.024 & 0.241 \\
\hline 9 & 0.020 & 0.014 & 0.022 & 0.021 & 0.317 \\
\hline High MAX & 0.021 & 0.011 & 0.031 & 0.027 & 0.555 \\
\hline \multirow[t]{2}{*}{ 10-1 difference } & 0.030 & 0.020 & 0.025 & 0.024 & \\
\hline & $(4.102)^{* * *}$ & $(3.724)^{* * *}$ & $(3.217)^{* * *}$ & $(3.342)^{* * *}$ & \\
\hline
\end{tabular}

Decile portfolios are formed every week from January 2014 to September 2020 by ranking cryptocurrencies based on the maximum daily return (MAX) within the past month. Decile 1 (10) is the portfolio of cryptocurrencies with the lowest (highest) maximum daily return over the previous month. Table presents the value-weighted (VW) and equal-weighted (EW) average weekly returns, three-factor alphas on the value-weighted and equal weighted portfolios, and average maximum daily returns of cryptocurrencies within the past month. The bottom two rows report the differences in weekly returns and the differences in alphas between portfolios 10 and 1, and the corresponding t-statistics. Newey-West (1987) adjusted t-statistics are presented in parentheses

****** and * denote significance at $1 \%, 5 \%$ and $10 \%$, respectively

momentum portfolios. The difference between the high MAX and low MAX valueweighted portfolio's three-factor alphas equals $1.99 \%$ with a Newey-West adjusted t-stat of 3.72, as shown in the last two rows of Table 2. The difference between the high MAX and low MAX equal-weighted portfolio alphas equals $2.44 \%$ with a Newey-West t-stat of 3.34. For both value-weighted and equal-weighted portfolios, the differences between average returns and three-factor alphas are both economically and statistically significant. In addition, we observe that as average MAX increases, both average returns and alphas increase monotonically. Contrary to the significant negative MAX effect in equity market (Bali et al. 2011; Hung and Yang 2018), these findings show that portfolios of cryptocurrencies with the highest extreme returns continue to exhibit superior performance in the future.

We repeat the univariate portfolio analysis by considering not only the unique extreme positive return (MAX) but also the averages of $N(N=2,3,4$, and 5$)$ highest daily returns within the past month, denoted by $\operatorname{MAX}(N)$. Table 3 presents the results of the analysis. Panel A reports the average return and alpha differences between the highest and lowest average $\operatorname{MAX}(N)$ for the value-weighted portfolios, and Panel B shows those for the equal-weighted portfolios. We also show the results from Table 2 in the first column of Table 3 for ease of comparison. The value-weighted and equal-weighted average raw return differences between the high $\operatorname{MAX}(N)$ and low $\operatorname{MAX}(N)$ remain economically and statistically significant.

Looking at Tables 2 and 3, we may argue that investors expect the extreme positive daily return behavior to last in the future and thus they may be willing to purchase these coins for higher prices. To understand the persistence of the MAX effect and to discuss the relationship between extreme positive returns and certain characteristics 
Table 3 Returns on portfolios of cryptocurrencies sorted by multi-day MAX

\begin{tabular}{|c|c|c|c|c|c|}
\hline Decile & $\mathrm{N}=1$ & $\mathbf{N}=\mathbf{2}$ & $\mathbf{N}=\mathbf{3}$ & $\mathrm{N}=4$ & $N=5$ \\
\hline \multicolumn{6}{|c|}{ Panel A. Value-weighted returns on MAX(N) portfolios } \\
\hline Low MAX(N) & -0.009 & -0.003 & -0.004 & -0.003 & -0.002 \\
\hline 2 & -0.007 & 0.002 & -0.001 & 0.000 & 0.001 \\
\hline 3 & -0.007 & -0.001 & -0.001 & -0.001 & -0.001 \\
\hline 4 & -0.007 & -0.001 & 0.006 & 0.008 & 0.002 \\
\hline 5 & 0.002 & 0.006 & 0.006 & 0.006 & 0.011 \\
\hline 6 & 0.000 & 0.002 & -0.001 & -0.002 & -0.003 \\
\hline 7 & 0.010 & 0.008 & 0.004 & 0.006 & 0.010 \\
\hline 8 & 0.007 & 0.009 & 0.011 & 0.007 & 0.006 \\
\hline 9 & 0.020 & 0.017 & 0.017 & 0.007 & 0.006 \\
\hline High $\operatorname{MAX}(\mathrm{N})$ & 0.021 & 0.022 & 0.014 & 0.020 & 0.023 \\
\hline \multirow[t]{2}{*}{ Return difference } & 0.030 & 0.026 & 0.018 & 0.023 & 0.025 \\
\hline & $(4.102)^{* * *}$ & $(3.235)^{* * *}$ & $(3.040)^{* * *}$ & $(2.212)^{* *}$ & $(2.447)^{* * *}$ \\
\hline \multirow[t]{2}{*}{ Alpha difference } & 0.020 & 0.024 & 0.023 & 0.019 & 0.016 \\
\hline & $(3.724)^{* * *}$ & $(3.525)^{* * *}$ & $(2.773)^{* * *}$ & $(2.431)^{* * *}$ & $(2.364)^{* * *}$ \\
\hline Decile & $\mathrm{N}=1$ & $\mathbf{N}=\mathbf{2}$ & $\mathbf{N}=3$ & $\mathrm{~N}=4$ & $\mathrm{~N}=5$ \\
\hline \multicolumn{6}{|c|}{ Panel B. Equal-weighted returns on MAX(N) portfolios } \\
\hline Low MAX(N) & 0.006 & 0.005 & 0.005 & 0.006 & 0.007 \\
\hline 2 & 0.016 & 0.017 & 0.014 & 0.015 & 0.016 \\
\hline 3 & 0.012 & 0.014 & 0.013 & 0.013 & 0.011 \\
\hline 4 & 0.013 & 0.013 & 0.021 & 0.023 & 0.016 \\
\hline 5 & 0.024 & 0.017 & 0.016 & 0.017 & 0.024 \\
\hline 6 & 0.016 & 0.019 & 0.016 & 0.015 & 0.013 \\
\hline 7 & 0.017 & 0.024 & 0.021 & 0.023 & 0.026 \\
\hline 8 & 0.027 & 0.028 & 0.029 & 0.023 & 0.022 \\
\hline 9 & 0.022 & 0.021 & 0.021 & 0.021 & 0.020 \\
\hline High MAX(N) & 0.031 & 0.027 & 0.026 & 0.029 & 0.032 \\
\hline \multirow[t]{2}{*}{ Return difference } & 0.025 & 0.022 & 0.021 & 0.023 & 0.025 \\
\hline & $(3.217)^{* * *}$ & $(2.903)^{* * *}$ & $(2.857)^{* * *}$ & $(3.051)^{* * *}$ & $(3.176)^{* * *}$ \\
\hline \multirow[t]{2}{*}{ Alpha difference } & 0.024 & 0.018 & 0.017 & 0.020 & 0.021 \\
\hline & $(3.342)^{* * *}$ & $(2.543)^{* * *}$ & $(2.484)^{* * *}$ & $(2.795)^{* * * *}$ & $(2.822)^{* * *}$ \\
\hline
\end{tabular}

Decile portfolios are formed every week from January 2014 to September 2020 by sorting cryptocurrencies based on the average of $N$ highest daily returns (MAX $(N)$ ) within the past month. Decile $1(10)$ is the portfolio of cryptocurrencies with the lowest (highest) maximum multi-day returns over the previous month. Table presents the value-weighted (VW) (in Panel A) and equal-weighted (EW) (in Panel B) average weekly returns for $N=1,2,3,4$, and 5 . The bottom two rows report the differences in weekly returns and the differences in three-factor alphas between portfolios 10 and 1, and the corresponding t-statistics. Newey-West (1987) adjusted t-statistics are presented in parentheses

$*^{* *},{ }^{* *}$ and ${ }^{*}$ denote significance at $1 \%, 5 \%$ and $10 \%$, respectively

of cryptocurrencies, we run the Fama and MacBeth (1973) regression models. In particular, for each week, we regress the maximum daily return within that particular month on the maximum daily return from the past month and seven lagged control variables. As explained in "Variable construction" section, our control variables are the market beta (BETA), the log of market capitalization (SIZE), the price of cryptocurrency (PRICE), the return over three weeks prior to the past week (MOM), the return in the previous week (REV), the Amihud illiquidity measure (ILLIQ), and the Garman-Klass volatility measure (VOL). For each of the 348 sample weeks, we winsorize all variables in the cross-section at $5 \%$ level from both upper and lower tails to 
Table 4 Cross-sectional predictability of MAX

\begin{tabular}{|c|c|c|c|c|c|c|c|c|}
\hline MAX & BETA & SIZE & PRICE & MOM & REV & ILLIQ & VOL & $R^{2}(\%)$ \\
\hline \multirow{16}{*}{$\begin{array}{l}0.957 \\
(90.128)^{* * *}\end{array}$} & & & & & & & & 68.57 \\
\hline & & & & & & & & \\
\hline & 0.413 & & & & & & & 11.37 \\
\hline & $(1.255)$ & & & & & & & \\
\hline & & -0.012 & & & & & & 8.22 \\
\hline & & $(-2.228)^{* *}$ & & & & & & \\
\hline & & & 0.083 & & & & & 6.98 \\
\hline & & & $(3.915)^{* * *}$ & & & & & \\
\hline & & & & 0.084 & & & & 11.11 \\
\hline & & & & $(3.371)^{* * *}$ & & & & \\
\hline & & & & & 0.109 & & & 13.36 \\
\hline & & & & & $(2.218)^{* *}$ & & & \\
\hline & & & & & & 1.540 & & 15.62 \\
\hline & & & & & & $(2.315)^{* *}$ & & \\
\hline & & & & & & & 0.242 & 36.27 \\
\hline & & & & & & & $(5.953)^{* * *}$ & \\
\hline 1.339 & 0.377 & -0.025 & 0.034 & -0.097 & 0.731 & 1.277 & 0.087 & 75.47 \\
\hline$(24.122)^{* * *}$ & $(0.907)$ & $(-1.014)$ & (1.106) & $(-0.818)$ & $(1.179)$ & $(0.201)$ & $(1.586)$ & \\
\hline
\end{tabular}

Each week, we conduct a cryptocurrency-level cross-sectional regression of the MAX on lagged explanatory variables, which are lagged MAX, BETA, SIZE, PRICE, MOM, REV, ILLIQ and VOL. MAX refers to the maximum daily return within a month. BETA is the market beta calculated as the sum of coefficients on lag, current and lead returns on market portfolio. SIZE equals the natural logarithm of the cryptocurrency's market capitalization by the end of previous week. PRICE is the natural logarithm of one plus the cryptocurrency's price. MOM stands for momentum that equals the cumulative return over the previous three weeks skipping past week. REV stands for short-term reversal and equals the return in the past week. ILLIQ refers to Amihud illiquidity measure, which is calculated by the ratio of absolute daily cryptocurrency return to its mean dollar trading volume. VOL refers to Garman-Klass volatility measure, which takes into account the highest, lowest, opening and closing prices. Both dependent and independent variables are winsorized at $5 \%$ level from upper and lower tails. Table reports the time-series averages of the cross-sectional regression coefficients and corresponding t-statistics. Newey-West (1987) adjusted $t$-statistics are presented in parentheses

$* * * * *$ and $*$ denote significance at $1 \%, 5 \%$ and $10 \%$, respectively

get rid of the outlier effect without removing any observation. Table 4 presents the average coefficients form cross-sectional regressions and the Newey-West adjusted t-statistics. The first two rows of Table 4 show that the coefficient of MAX variable is positive with an extremely high statistical significance and the adjusted R-squared value over $68 \%$. When we add the seven control variables to the regression, MAX coefficient remains positive and highly significant with the adjusted R-squared of over $75 \%$ while all other variables become insignificant. This significant explanatory power of MAX in the univariate regression on lagged MAX and multivariate regression with additional seven lagged variables indicate that a positive relation exists between the maximum daily return over the previous month and expected extreme positive cryptocurrency returns. In other words, coins with extreme positive returns are inclined to outperform in the following month.

We further investigate the two extreme deciles (low MAX and high MAX) in the post-formation period and report the descriptive statistics in Table 5. We use approximately 55,000 weekly returns on cryptocurrencies. Unlike the equal-weighted portfolio calculation in Table 2 with different number of coins, we weigh all returns equally as presented in the first row of Table 5. For this reason, the mean return for 
Table 5 Distribution of weekly returns for cryptocurrencies in high and low MAX portfolios

\begin{tabular}{lrr}
\hline & Low MAX & High MAX \\
\hline Mean & 0.005 & 0.038 \\
Median & -0.001 & -0.003 \\
Std dev & 0.155 & 0.251 \\
Skewness & 2.570 & 2.919 \\
Percentiles & & \\
$1 \%$ & -0.352 & -0.371 \\
$5 \%$ & -0.213 & -0.262 \\
$10 \%$ & -0.154 & -0.199 \\
$25 \%$ & -0.061 & -0.126 \\
$50 \%$ & -0.001 & -0.003 \\
$75 \%$ & 0.050 & 0.155 \\
$90 \%$ & 0.159 & 0.337 \\
$95 \%$ & 0.256 & 0.430 \\
$99 \%$ & 0.505 & 0.722 \\
\hline
\end{tabular}

Decile portfolios are formed every week from January 2014 to September 2020 by sorting cryptocurrencies according to maximum daily return (MAX) within the previous month. The table presents descriptive statistics for the approximately 55.000 weekly returns on the coins in decile 1 (low MAX) and decile 10 (high MAX) in the subsequent week

low MAX is lower than the equal-weighted portfolio average return (in Table 2), and the mean return for high MAX is higher than that of Table 2. When compared to low MAX coins, high MAX coins have higher average returns with higher volatility and slightly more positive skewness. Moreover, upper tail behavior in percentiles presents that the high MAX returns at 90th, 95th, and 99th percentiles are nearly twofold of low MAX returns. The results demonstrate that there is a higher probability for high MAX coins to preserve extreme positive returns in the future.

The analyses thus far uncover some evidence against the investor preference over lottery-like assets, which have a slight chance of a large future payoff in the future (Kumar 2009; Bali et al. 2011). The MAX variable with a characteristic of high positive skewness construct a suitable basis for lottery-like behavior (Fong and Toh 2014; Zhu et al. 2020). However, in the cryptocurrency market, we observe that if we buy a well performing coin portfolio and sell a poorly performing portfolio, there is a high probability of continuing to win significant positive returns in the future. Hence, the behavior of the cryptocurrency market signals inefficiency and resembles movement direction of the momentum factor (Jegadeesh and Titman 1993). To understand more about the MAX portfolio composition, we report the summary statistics of cryptocurrencies in the decile portfolios in Table 6. The table presents the averages of the weekly median values of characteristics, which are the maximum daily return (MAX), the cryptocurrency market beta, the market capitalization (in millions of dollars), the price (in dollars), the cumulative return over the previous three weeks prior to the week before (MOM), the cumulative return over the past week (REV), the Amihud illiquidity measure (scaled by $10^{-5}$ ), and the Garman-Klass volatility measure.

Table 6 shows that as we move from decile 1 (low MAX) to decile 10 (high MAX), the average of weekly median MAX values increase from $5.38 \%$ to $59.56 \%$ whereas the size values decrease from $\$ 426.75$ million to $\$ 21.92$ million. This indicates that high 
Table 6 Summary statistics for decile portfolios of stocks sorted by MAX

\begin{tabular}{lllllllll}
\hline Decile & MAX & BETA & SIZE $\left(\$ 10^{6}\right)$ & PRICE (\$) & MOM & REV & ILLIQ $\left(\mathbf{1 0}^{-5}\right)$ & VOL \\
\hline Low MAX & 0.054 & 0.693 & 426.752 & 0.982 & -0.030 & -0.019 & 0.027 & 0.376 \\
2 & 0.083 & 0.871 & 354.295 & 0.762 & -0.036 & -0.015 & 0.033 & 0.546 \\
3 & 0.100 & 0.868 & 150.015 & 0.558 & -0.021 & -0.014 & 0.042 & 0.605 \\
4 & 0.126 & 0.908 & 251.399 & 0.668 & -0.011 & -0.006 & 0.066 & 0.680 \\
5 & 0.132 & 0.801 & 129.025 & 0.427 & 0.022 & 0.000 & 0.061 & 0.657 \\
6 & 0.169 & 0.905 & 174.171 & 0.518 & 0.025 & 0.009 & 0.070 & 0.776 \\
7 & 0.199 & 0.916 & 135.694 & 0.532 & 0.059 & 0.012 & 0.088 & 0.852 \\
8 & 0.241 & 0.889 & 27.440 & 0.367 & 0.076 & 0.021 & 0.078 & 0.896 \\
9 & 0.314 & 0.839 & 35.708 & 0.313 & 0.128 & 0.042 & 0.129 & 0.961 \\
High MAX & 0.596 & 0.942 & 21.916 & 0.350 & 0.245 & 0.077 & 0.285 & 1.389 \\
\hline
\end{tabular}

Decile portfolios are formed every week from January 2014 to September 2020 by ranking cryptocurrencies based on the maximum daily return (MAX) within the past month. Decile 1 (10) is the portfolio of cryptocurrencies with the lowest (highest) maximum daily return over the previous month. Table presents the averages of weekly median values of each decile for various characteristics of cryptocurrencies - the maximum daily return (MAX), the cryptocurrency market beta, the market capitalization (in millions of dollars), the price (in dollars), the cumulative return over the previous three weeks prior to the week before (MOM), the cumulative return over the past week (REV), the Amihud illiquidity measure (scaled by $10^{-5}$ ), and the Garman-Klass volatility measure

MAX portfolios are dominated by smaller-sized cryptocurrencies. This result is consistent with the findings of Chan et al. (1991) and Fama and French (1992) who document the high likelihood of relatively smaller firms to return higher profits. As the average of median daily maximum return increases through decile 1 to decile 10 , the price also diminishes. The increase in the market beta indicates that cryptocurrencies in high MAX decile are slightly more exposed to market risk. The average values of the median momentum and short-term reversal variables both rise as we move from low MAX decile to high MAX decile. These findings also support that past winners continue to perform better in the future (Jegadeesh and Titman 1993). Furthermore, a mild increase exists in the illiquidity measure. Specifically, high MAX coins are found to be less liquid and more volatile. This contrary relationship is consistent with the findings of Wei (2018).

\section{Bivariate portfolio analysis}

In this section, our goal is to understand whether the relationship between maximum daily returns and future returns on cryptocurrencies persists as discussed, when we control for size, price, momentum, short-term reversal, and liquidity. Following Bali et al. (2011), we perform the bivariate portfolio analysis where we first sort cryptocurrencies by a certain characteristic (such as size). We then categorize each of these deciles according to MAX. Thus, we obtain 100 cryptocurrency portfolios. Table 7 presents the results for MAX portfolio deciles by averaging across the ten deciles sorted by the characteristics. ${ }^{13}$ Average returns and corresponding alphas for value-weighted portfolios and equal-weighted portfolios are reported in Panel A and Panel B of Table 7, respectively.

Bivariate portfolio analysis presents the supporting evidence for our findings in "Univariate portfolio analysis" section. When we control for size, the value-weighted mean

\footnotetext{
${ }^{13}$ We do not report the findings of all 100 portfolios for brevity; however, comprehensive results are available upon request.
} 
Table 7 Returns on portfolios of cryptocurrencies sorted by MAX after controlling for SIZE, PRICE, MOM, REV, and ILLIQ

\begin{tabular}{|c|c|c|c|c|c|}
\hline Decile & SIZE & PRICE & MOM & REV & ILLIQ \\
\hline \multicolumn{6}{|c|}{ Panel A. Value-weighted portfolio returns } \\
\hline Low MAX & 0.010 & 0.009 & 0.007 & 0.010 & 0.010 \\
\hline 2 & 0.018 & 0.014 & 0.016 & 0.012 & 0.017 \\
\hline 3 & 0.013 & 0.013 & 0.014 & 0.010 & 0.012 \\
\hline 4 & 0.016 & 0.014 & 0.010 & 0.014 & 0.011 \\
\hline 5 & 0.012 & 0.010 & 0.011 & 0.013 & 0.010 \\
\hline 6 & 0.021 & 0.016 & 0.016 & 0.016 & 0.019 \\
\hline 7 & 0.020 & 0.014 & 0.013 & 0.012 & 0.014 \\
\hline 8 & 0.018 & 0.013 & 0.016 & 0.013 & 0.015 \\
\hline 9 & 0.016 & 0.010 & 0.011 & 0.010 & 0.008 \\
\hline High MAX & 0.038 & 0.027 & 0.024 & 0.025 & 0.028 \\
\hline \multirow[t]{2}{*}{ Return difference } & 0.027 & 0.017 & 0.017 & 0.015 & 0.018 \\
\hline & $(7.702)^{* * *}$ & $(5.555)^{* * *}$ & $(5.188)^{* * *}$ & $(4.344)^{* * *}$ & $(5.244)^{* * *}$ \\
\hline \multirow[t]{2}{*}{ Alpha difference } & 0.025 & 0.015 & 0.014 & 0.012 & 0.014 \\
\hline & $(2.713)^{* * *}$ & $(2.859)^{* * *}$ & $(5.246)^{* * *}$ & $(3.743)^{* * *}$ & $(2.867)^{* * *}$ \\
\hline Decile & SIZE & PRICE & MOM & REV & ILLIQ \\
\hline \multicolumn{6}{|c|}{ Panel B. Equal-weighted portfolio returns } \\
\hline Low MAX & 0.007 & 0.009 & 0.007 & 0.009 & 0.009 \\
\hline 2 & 0.015 & 0.013 & 0.014 & 0.011 & 0.014 \\
\hline 3 & 0.010 & 0.013 & 0.012 & 0.010 & 0.010 \\
\hline 4 & 0.012 & 0.013 & 0.009 & 0.013 & 0.011 \\
\hline 5 & 0.009 & 0.009 & 0.009 & 0.012 & 0.009 \\
\hline 6 & 0.016 & 0.014 & 0.014 & 0.015 & 0.016 \\
\hline 7 & 0.015 & 0.013 & 0.012 & 0.011 & 0.011 \\
\hline 8 & 0.012 & 0.011 & 0.015 & 0.011 & 0.013 \\
\hline 9 & 0.009 & 0.009 & 0.010 & 0.008 & 0.006 \\
\hline High MAX & 0.028 & 0.027 & 0.025 & 0.026 & 0.025 \\
\hline \multirow[t]{2}{*}{ Return difference } & 0.021 & 0.018 & 0.018 & 0.017 & 0.016 \\
\hline & $(6.197)^{* * *}$ & $(6.072)^{* * *}$ & $(5.772)^{* * *}$ & $(5.310)^{* * *}$ & $(4.839)^{* * *}$ \\
\hline \multirow[t]{2}{*}{ Alpha difference } & 0.019 & 0.016 & 0.016 & 0.015 & 0.013 \\
\hline & $(2.043)^{* *}$ & $(2.813)^{* * *}$ & $(4.807)^{* * *}$ & $(3.775)^{* * *}$ & $(2.592)^{* * *}$ \\
\hline
\end{tabular}

Decile portfolios are formed every week from January 2014 to September 2020 by sorting cryptocurrencies based on the maximum daily returns after controlling for size, price, momentum, short-term reversal, and illiquidity. In each column, we first rank cryptocurrencies based on the control variable, then within each decile, we sort cryptocurrencies into decile portfolios of MAX. Decile 1 (10) is the portfolio of cryptocurrencies with the lowest (highest) maximum daily return over the previous month. Table presents the value-weighted (VW) (in Panel A) and equal-weighted (EW) (in Panel B) average weekly returns. The bottom two rows report the differences in weekly returns and the differences in three-factor alphas between portfolios 10 and 1, and the corresponding t-statistics. Newey-West (1987) adjusted t-statistics are presented in parentheses $* * * * *$ and ${ }^{*}$ denote significance at $1 \%, 5 \%$ and $10 \%$, respectively

return difference between decile 10 (high MAX) and decile 1 (low MAX) is $2.73 \%$ with a Newey-West adjusted $t$-stat of 7.70. Furthermore, the corresponding value for the value-weighted average risk-adjusted return difference equals $2.47 \%$ with a t-stat of 2.71 . Similarly, after controlling for price, momentum, short-term reversal, and liquidity, the value-weighted average return differences between the high MAX and low MAX portfolios are $1.75 \%, 1.69 \%, 1.48 \%$, and $1.76 \%$ per week, respectively. For equal-weighted portfolios, average return differences between high MAX and low MAX portfolios are $2.08 \%, 1.82 \%, 1.77 \%, 1.70 \%$, and $1.56 \%$ per week, respectively. All mean raw differences 
Table 8 Cross-sectional return regressions

\begin{tabular}{|c|c|c|c|c|c|c|}
\hline MAX & BETA & SIZE & PRICE & MOM & REV & ILLIQ \\
\hline \multirow{2}{*}{\multicolumn{7}{|c|}{$\begin{array}{l}0.082 \\
(3.135)^{* * *}\end{array}$}} \\
\hline & & & & & & \\
\hline & 0.016 & & & & & \\
\hline & $(0.200)$ & & & & & \\
\hline & & -0.001 & & & & \\
\hline & & $(-2.730)^{* * *}$ & & & & \\
\hline & & & 0.008 & & & \\
\hline & & & $(2.624)^{* * *}$ & & & \\
\hline & & & & 0.039 & & \\
\hline & & & & $(2.315)^{* *}$ & & \\
\hline & & & & & 0.096 & \\
\hline & & & & & $(2.634)^{* * *}$ & \\
\hline & & & & & & 1.586 \\
\hline & & & & & & $(0.970)$ \\
\hline & 0.049 & -0.002 & 0.003 & 0.022 & -0.005 & 0.847 \\
\hline & $(1.170)$ & $(-0.763)$ & $(0.868)$ & $(0.734)$ & $(-0.122)$ & $(0.228)$ \\
\hline 0.284 & 0.012 & -0.006 & 0.007 & 0.015 & 0.013 & 3.538 \\
\hline$(6.136)^{* * *}$ & $(0.314)$ & $(-1.022)$ & $(1.257)$ & $(0.209)$ & $(0.334)$ & $(0.524)$ \\
\hline
\end{tabular}

Each week from January 2014 to September 2020, we conduct a cryptocurrency-level cross-sectional regression of the return in that week on lagged explanatory variables, which are lagged MAX, BETA, SIZE, PRICE, MOM, REV, and ILLIQ. MAX refers to the maximum daily return within a month. BETA is the market beta calculated as the sum of coefficients on lag, current and lead returns on market portfolio. SIZE equals the natural logarithm of the cryptocurrency's market capitalization by the end of previous week. PRICE is the natural logarithm of one plus the cryptocurrency's price. MOM stands for momentum that equals the cumulative return over the previous three weeks skipping past week. REV stands for short-term reversal and equals the return in the past week. ILLIQ refers to Amihud illiquidity measure, which is calculated by the ratio of absolute daily cryptocurrency return to its mean dollar trading volume. Both dependent and independent variables are winsorized at $5 \%$ level from upper and lower tails. Table reports the time-series averages of the cross-sectional regression coefficients and corresponding t-statistics. Newey-West (1987) adjusted t-statistics are presented in parentheses

***** and ${ }^{*}$ denote significance at $1 \%, 5 \%$ and $10 \%$, respectively

are economically and statistically significant. For value-weighted and equal-weighted portfolios, the differences between alpha values of high MAX and low MAX coins are statistically significant. As these results coincide with the findings of univariate portfolio studies, none of the cross-sectional effects, such as size, price, momentum, short-term reversal nor liquidity is powerful enough to explain further the highest extreme returns to high MAX cryptocurrencies.

\section{Cross-sectional return regressions}

The portfolio analyses we have conducted thus far give supporting results of a positive MAX effect. In this section, we investigate the coin level cross-sectional relation between MAX and expected returns to observe whether a connection exists at the individual level. ${ }^{14}$ We run Fama and Macbeth regressions of cryptocurrency returns on the lagged maximum daily return (MAX), market beta (BETA), log of market capitalization (SIZE), price of cryptocurrency (PRICE), return over three weeks prior to the past

${ }^{14}$ Refer to Liu and Tsyvinski (2018) and Liu et al. (2019) for excellent studies on cross-sectional cryptocurrency returns and predictability. 
Table 9 Time-series averages of cross-sectional correlations

\begin{tabular}{lllllll}
\hline & MAX & MAX(5) & MIN & TVOL & IVOL & VOL \\
\hline MAX & 1 & & & & & \\
MAX(5) & 0.9978 & 1 & & & & \\
MIN & -0.0354 & 0.0107 & 1 & & & \\
TVOL & 0.7695 & 0.7716 & -0.0219 & 1 & 1 \\
IVOL & 0.7957 & 0.7525 & 0.6506 & 0.9881 & 0.0013 & 1 \\
VOL & 0.0028 & 0.0036 & 0.5538 & 0.0042 & 0 \\
\hline
\end{tabular}

Table reports the averages of the weekly cross-sectional correlations of the maximum daily return in a month (MAX), the average of the highest five daily returns in a month $(\operatorname{MAX}(5))$, the minimum daily return in a month (MIN), total volatility (TVOL), idiosyncratic volatility (IVOL), and Garman-Klass volatility (VOL)

week (MOM), return in the previous week (REV), and the Amihud illiquidity measure (ILLIQ), as shown in Eq. (5).

$$
\begin{array}{r}
\mathrm{R}_{i, t+1}=\gamma_{0, t}+\gamma_{1, t}\left(M A X_{i, t}\right)+\gamma_{2, t}\left(B E T A_{i, t}\right)+\gamma_{3, t}\left(\operatorname{SIZE}_{i, t}\right)+\gamma_{4, t}\left(\operatorname{PRICE}_{i, t}\right) \\
+\gamma_{5, t}\left(\operatorname{MOM}_{i, t}\right)+\gamma_{6, t}\left(\operatorname{REV}_{i, t}\right)+\gamma_{7, t}\left(I L L I Q_{i, t}\right)+\epsilon_{i, t+1}
\end{array}
$$

where $\mathrm{R}_{i, t+1}$ is the realized return on cryptocurrency $i$ in week $t+1$, and all independent variables are lagged one week. Rules on winsorization still apply. Table 8 presents the time-series averages of the slope coefficients over 348 weeks from January 2014 to September 2020.

The univariate regression of maximum daily return on future cryptocurrency returns results in a positive and statistically significant relationship. The average slope, $\gamma_{1, t}$, equals $8.21 \%$ with a robust $\mathrm{t}$-stat of 3.14. Considering the spread between median of MAX between decile 10 and decile 1 from Table 6, we can estimate approximately 445 basis points difference in the expected weekly returns among high MAX and low MAX deciles of median coins. The economic magnitude of this difference is extremely significant as well as encouraging for the investors to buy cryptocurrencies with the highest daily extreme returns. In addition to MAX, the univariate regressions show that SIZE and PRICE have an explanatory power over the expected returns, which is consistent with the findings of $\mathrm{Li}$ et al. (2020b). The average slopes of MOM (3.92\%) and REV (9.62\%) variables are positive and significant at $5 \%$ and $1 \%$, respectively. Momentum having a positive explanatory power over future returns coincides with the findings of Liu et al. (2020) while contradicting with the results of Grobys and Sapkota (2019). When the regression is run with the six control variables except MAX, no significant explanatory variable is found. Nevertheless, as shown in the last row of Table 8 , when we embrace all variables in the regression, MAX shows a higher significance with a coefficient of $28.43 \%$ and a t-stat of 6.14 . The regression results show that, contrary to Jia et al. (2020), the cross-sectional regressions are a strong evidence for an economically and statistically significant positive relation between extreme returns and expected returns in the cryptocurrency market. 


\section{Extreme positive returns and volatility}

The literature on cross-sectional studies of volatility and expected return have revealed inconsistent results (Ang et al. 2006; Bali and Cakici 2008; Fu 2009). In the cryptocurrency market, Zhang and $\mathrm{Li}$ (2020) report a positive and nontemporal relationship between idiosyncratic volatility and future returns using more than 500 coins. In particular, cryptocurrencies with a high maximum daily return within a month also have high volatility, as shown in Table 6. Depending on the substantial connection between idiosyncratic volatility and maximum daily returns, we examine whether MAX effect acts as a proxy for volatility; this section investigates in detail the relation among them. First, Table 9 shows the average weekly cross-sectional correlation coefficients between six variables: the maximum daily return within the past month (MAX), average of the highest five daily returns within the past month $(\operatorname{MAX}(5))$, the minimum daily return within the past month (MIN) as described in Eq. (6), monthly realized total volatility (TVOL) as described in Eq. (7), monthly realized idiosyncratic volatility (IVOL) as described in Eq. (8), the and Garman-Klass volatility (VOL).

$$
\operatorname{MIN}_{i, t}=\min \left(R_{i, d}\right), \quad d=1, \ldots, D_{m}
$$

where $\mathrm{R}_{i, d}$ is the return on cryptocurrency $i$ on day $d$ and $D_{m}$ is the number of trading days in month $m$,

$$
\begin{aligned}
\operatorname{TVOL}_{i, t} & =\sqrt{\operatorname{var}\left(R_{i, d}\right)} \\
\mathrm{IVOL}_{i, t} & =\sqrt{\operatorname{var}\left(\epsilon_{i, d}\right)}
\end{aligned}
$$

with $\epsilon_{i, d}$ is the innovation on cryptocurrency obtained from Eq. (9).

$$
\mathrm{R}_{i, d}-r_{f, d}=\alpha_{i}+\beta_{1, i}\left(R_{m, d}-r_{f, d}\right)+\epsilon_{i, d}
$$

Table 9 shows that in our cryptocurrency sample, very high average cross-sectional correlations exist between TVOL and IVOL (coefficient of 0.99), TVOL and MAX (coefficient of 0.77), and IVOL and MAX (coefficient of 0.80). MAX and MAX(5) are highly correlated as expected, which indicates that they can act as perfect substitutes for each other. On the contrary, there is a very low correlation between Garman-Klass volatility (VOL) and maximum daily return (MAX), which is why we use this variable as the volatility factor in our analysis.

Second, we perform the bivariate portfolio analysis to further examine the relationship between volatility and expected returns on cryptocurrencies. Similarly, as discussed in "Bivariate portfolio analysis" section and presented in Table 7, we sort cryptocurrencies by MAX, controlling for VOL and IVOL. In order to do that, we form decile portfolios that are sorted based on VOL and IVOL. We then rank each volatility decile according to MAX and conduct value-weighted and equal-weighted portfolio analysis. ${ }^{15}$ The results for average returns across MAX deciles, the corresponding three-factor alphas,

\footnotetext{
15 We repeat the same bivariate portfolio analysis by replacing MAX with MAX(5) and obtain very similar results to those reported in Table 10. For brevity, we do not report these findings in the paper, but the results are available upon request.
} 
Table 10 Returns on portfolios of cryptocurrencies sorted by MAX and volatility after controlling for volatility and MAX

\begin{tabular}{|c|c|c|c|c|}
\hline \multirow[t]{2}{*}{ Decile } & \multicolumn{2}{|l|}{ VOL } & \multicolumn{2}{|l|}{ IVOL } \\
\hline & vW & EW & vw & EW \\
\hline \multicolumn{5}{|c|}{ Panel A. Sorted by MAX controlling for VOL and IVOL } \\
\hline Low MAX & 0.009 & 0.008 & 0.015 & 0.014 \\
\hline 2 & 0.014 & 0.012 & 0.018 & 0.016 \\
\hline 3 & 0.012 & 0.011 & 0.012 & 0.011 \\
\hline 4 & 0.011 & 0.010 & 0.013 & 0.011 \\
\hline 5 & 0.009 & 0.008 & 0.012 & 0.010 \\
\hline 6 & 0.013 & 0.012 & 0.013 & 0.013 \\
\hline 7 & 0.017 & 0.015 & 0.008 & 0.007 \\
\hline 8 & 0.014 & 0.012 & 0.008 & 0.007 \\
\hline 9 & 0.007 & 0.008 & 0.008 & 0.006 \\
\hline High MAX & 0.025 & 0.028 & 0.024 & 0.024 \\
\hline \multirow[t]{2}{*}{ Return difference } & 0.016 & 0.020 & 0.009 & 0.010 \\
\hline & $(5.173)^{* * *}$ & $(6.762)^{* * *}$ & $(2.720)^{* * *}$ & $(2.982)^{* * *}$ \\
\hline \multirow[t]{3}{*}{ Alpha difference } & 0.013 & 0.018 & 0.006 & 0.007 \\
\hline & $(2.644)^{* * *}$ & $(3.455)^{* * *}$ & $(2.128)^{* *}$ & $(2.031)^{* *}$ \\
\hline & \multicolumn{2}{|l|}{ VOL } & \multicolumn{2}{|l|}{ IVOL } \\
\hline Decile & VW & EW & vw & EW \\
\hline \multicolumn{5}{|c|}{ Panel B. Sorted by VOL and IVOL controlling for MAX } \\
\hline Low Volatility & 0.016 & 0.019 & 0.014 & 0.016 \\
\hline 2 & 0.014 & 0.014 & 0.008 & 0.008 \\
\hline 3 & 0.010 & 0.011 & 0.013 & 0.011 \\
\hline 4 & 0.013 & 0.011 & 0.013 & 0.012 \\
\hline 5 & 0.007 & 0.006 & 0.007 & 0.006 \\
\hline 6 & 0.016 & 0.015 & 0.014 & 0.012 \\
\hline 7 & 0.011 & 0.010 & 0.011 & 0.009 \\
\hline 8 & 0.013 & 0.011 & 0.010 & 0.010 \\
\hline 9 & 0.007 & 0.006 & 0.008 & 0.008 \\
\hline High Volatility & 0.020 & 0.019 & 0.028 & 0.028 \\
\hline \multirow[t]{2}{*}{ Return difference } & 0.004 & 0.001 & 0.014 & 0.012 \\
\hline & $(1.417)$ & $(0.239)$ & $(1.287)$ & $(1.112)$ \\
\hline \multirow[t]{2}{*}{ Alpha difference } & 0.002 & 0.002 & 0.011 & 0.010 \\
\hline & $(0.641)$ & $(0.621)$ & $(0.647)$ & $(0.741)$ \\
\hline
\end{tabular}

Double-sorted, value-weighted (VW) and equal-weighted (EW) decile portfolios are formed every week from January 2014 to September 2020. In Panel A, cryptocurrencies are sorted based on the maximum daily returns after controlling for volatility (VOL and IVOL). In Panel B, cryptocurrencies are sorted based on the volatility (VOL and IVOL) after controlling for the maximum daily returns. VOL refers to Garman-Klass volatility and IVOL refers to the idiosyncratic volatility. Decile 1 (10) is the portfolio of cryptocurrencies with the lowest (highest) maximum daily return over the previous month. Table presents the value-weighted (VW) and equal-weighted (EW) average weekly returns. The bottom two rows report the differences in weekly returns and the differences in three-factor alphas between portfolios 10 and 1, and the corresponding t-statistics. Newey-West (1987) adjusted t-statistics are presented in parentheses

***, ** and * denote significance at $1 \%, 5 \%$ and $10 \%$, respectively

and the Newey-West adjusted t-statistics are shown in Panel A of Table 10. The valueweighted average raw difference between decile 10 (high MAX) and decile 1 (low MAX) is $1.58 \%(0.91 \%)$ per week with a t-stat of 5.17 (2.72) when we control for VOL (IVOL). Alpha values are also economically and statistically significant. By allowing deciles to contain cryptocurrencies with all levels of volatility and dispersion based on MAX, we 
Table 11 Cross-sectional return regressions with MAX, MIN and VOL

\begin{tabular}{|c|c|c|c|c|c|c|c|c|}
\hline MAX & VOL & MIN & BETA & SIZE & PRICE & MOM & REV & ILLIQ \\
\hline \multicolumn{9}{|l|}{0.082} \\
\hline \multicolumn{9}{|l|}{$(3.135)^{* * *}$} \\
\hline & 0.017 & & & & & & & \\
\hline & $(1.510)$ & & & & & & & \\
\hline 0.331 & -0.010 & & & & & & & \\
\hline$(9.794)^{* * *}$ & -0.909 & & & & & & & \\
\hline 0.447 & 0.005 & & 0.046 & -0.005 & 0.009 & 0.062 & 0.046 & 1.545 \\
\hline \multirow[t]{3}{*}{$(3.828)^{* * *}$} & $(0.125)$ & & $(0.704)$ & $(-1.041)$ & $(0.984)$ & $(1.850)^{*}$ & $(2.514)^{* * *}$ & $(0.924)$ \\
\hline & & 0.094 & & & & & & \\
\hline & & $(2.312)^{* *}$ & & & & & & \\
\hline 0.325 & & -0.024 & & & & & & \\
\hline$(9.917)^{* * *}$ & & $(-0.423)$ & & & & & & \\
\hline 0.363 & & -0.889 & -0.012 & 0.010 & -0.017 & 0.367 & 0.078 & 1.146 \\
\hline$(3.964)^{* * *}$ & & $(-1.055)$ & $(-0.233)$ & $(1.217)$ & $(-1.071)$ & $(1.957)^{*}$ & $(2.051)^{* *}$ & $(0.531)$ \\
\hline 0.388 & 0.023 & -0.105 & & & & & & \\
\hline$(10.178)^{* * *}$ & $(1.017)$ & $(-1.383)$ & & & & & & \\
\hline 0.441 & 0.045 & 0.225 & 0.018 & -0.001 & -0.002 & 0.046 & 0.148 & 0.597 \\
\hline$(3.475)^{* * *}$ & $(0.515)$ & $(0.885)$ & $(0.206)$ & $(-0.217)$ & $(-0.236)$ & $(1.881)^{*}$ & $(2.130)^{* *}$ & $(0.255)$ \\
\hline
\end{tabular}

Each week from January 2014 to September 2020, we conduct a cryptocurrency-level cross-sectional regression of the return in that week on lagged explanatory variables, which are lagged MAX, MIN and VOL as well as six other control variables - BETA, SIZE, PRICE, MOM, REV and ILLIQ. MAX refers to the maximum daily return within a month. MIN refers to the minimum daily return within a month. VOL refers to Garman-Klass volatility measure, which takes into account the highest, lowest, opening and closing prices. BETA is the market beta calculated as the sum of coefficients on lag, current and lead returns on market portfolio. SIZE equals the natural logarithm of the cryptocurrency's market capitalization by the end of previous week. PRICE is the natural logarithm of one plus the cryptocurrency's price. MOM stands for momentum that equals the cumulative return over the previous three weeks skipping past week. REV stands for short-term reversal and equals the return in the past week. ILLIQ refers to Amihud illiquidity measure, which is calculated by the ratio of absolute daily cryptocurrency return to its mean dollar trading volume. Both dependent and independent variables are winsorized at $5 \%$ level from upper and lower tails. Table reports the time-series averages of the cross-sectional regression coefficients and corresponding t-statistics. Newey-West (1987) adjusted t-statistics are presented in parentheses

***, ** and * denote significance at $1 \%, 5 \%$ and $10 \%$, respectively

show that the power of MAX effect to explain future returns persists. In addition to value-weighted portfolios, the differences between high MAX and low MAX deciles and their significance levels are conformable to those in Tables 3 and 7.

Furthermore, in Panel B of Table 10, we conduct the reverse sort. We form deciles of cryptocurrencies ranked by IVOL and VOL, controlling for extreme positive returns. The average raw differences between the high VOL and low VOL deciles of both valueweighted and equal-weighted portfolios as well as three factor alpha differences remain insignificant. The results in Table 10 report no effect of volatility and idiosyncratic volatility on future returns, which is consistent with the findings of Bali and Cakici (2008) but contradicts with the significant positive relation indicated by Zhang and Li (2020). We observe that when we control for volatility and idiosyncratic volatility, coins with extreme positive returns continue to show superior performance in the future. However, when the data is controlled for MAX, the effect of volatility and idiosyncratic volatility on future returns disappear. This analysis further sheds light on the positive relation between the highest extreme returns and expected returns in the cryptocurrency market. 
Third, we investigate the cross-sectional relationship between volatility and expected returns. Table 11 presents the results of Fama-Macbeth regressions. Rules on winsorization still apply. In univariate regressions, the average slope of MAX is $8.21 \%$ with a $\mathrm{t}$-stat of 3.14. However, the volatility coefficient $(1.68 \%)$ is not significant $(\mathrm{t}$-stat=1.51), which supports the finding that volatility remains inefficient in explaining future returns in equal-weighted portfolios. ${ }^{16}$ When future returns are regressed on MAX and volatility together, the significance of MAX increases whereas VOL remains insignificant with a negative coefficient. When six other control variables are added to the regression, the insignificance of VOL remains unchanged. We might suspect that the positive relation between idiosyncratic volatility and expected returns reported by Zhang and $\mathrm{Li}$ (2020) is reasoning from the fact that IVOL acts as a proxy for MAX. Furthermore, we consider MIN in our regression analysis to further understand the effect of volatility. As MIN is also highly correlated with volatility, it might exhibit a similar behavior with MAX if our results are a consequence of volatility effect. Table 11 also shows the Fama-Macbeth regression results with MAX, MIN, and VOL. The univariate regression coefficient of MIN is $9.36 \%$ with a $t$-stat of 2.31 , which is significant at $5 \%$ level. The positive sign of MIN might indicate that a decrease in a cryptocurrency's value does not necessarily mean lower future returns. In all of 7 regressions presented in Table 11, MAX coefficient remains statistically significant after controlling for MIN, VOL, BETA, SIZE, PRICE, MOM, REV, and ILLIQ. These results confirm our findings in univariate and bivariate analyses with the interpretation that in the cryptocurrency market, the MAX effect is not temporal and a positive relation exists between the highest extreme returns and future expected returns.

\section{Extreme positive returns and skewness}

In this section, we investigate the connection between extreme positive returns and skewness. The literature highlights investor preference over positive skewness (Arditti 1967; Kraus and Litzenberger 1976; Scott and Horvath 1980). Harvey and Siddique (2000) shows the relationship between momentum effect and systematic skewness. By measuring conditional skewness, Harvey and Siddique (2000) and Smith (2007) indicate that portfolios with a higher skewness tend to underperform in the future. In addition, Mitton and Vorkink (2007) and Boyer et al. (2010) find negative correlation among idiosyncratic skewness and expected returns. Nevertheless, Brunnermeier and Gollier (2007) and Barberis and Huang (2008) show that at least theoretically, skewness is not the reason for these underperforming stocks. On the contrary, Wei (2018) reports strong positive skewness in cryptocurrency returns whereas Balcilar et al. (2017) show that Bitcoin returns are left-skewed. Jia et al. (2020) document that extreme positive returns have a significant effect over return predictability of higher moments. Considering the literature on the impact of skewness on expected returns, we question whether the MAX effect is robust to controls for skewness measures. We use two different measures to evaluate skewness, total skewness (TSKEW), and idiosyncratic skewness (ISKEW).

\footnotetext{
${ }^{16}$ In cross-sectional regressions, the averaging process weigh each coin equally.
} 
Table 12 Returns on portfolios of cryptocurrencies sorted by MAX after controlling for skewness

\begin{tabular}{lll}
\hline Decile & TSKEW & ISKEW \\
\hline Low MAX & 0.008 & 0.009 \\
2 & 0.012 & 0.012 \\
3 & 0.012 & 0.010 \\
4 & 0.013 & 0.015 \\
5 & 0.009 & 0.009 \\
6 & 0.017 & 0.012 \\
7 & 0.013 & 0.009 \\
8 & 0.012 & 0.012 \\
9 & 0.011 & 0.012 \\
High MAX & 0.038 & 0.035 \\
Return difference & 0.029 & 0.027 \\
Alpha difference & $(8.064)^{* * *}$ & $(7.375)^{* * *}$ \\
& 0.027 & 0.024 \\
\hline
\end{tabular}

Decile portfolios are formed every week from January 2014 to September 2020 by sorting cryptocurrencies based on the maximum daily returns after controlling for total (TSKEW) and idiosyncratic (ISKEW). In each column, we first rank cryptocurrencies based on the skewness variable (TSKEW and ISKEW), then within each decile, we sort cryptocurrencies into decile portfolios of MAX. Decile 1 (10) is the portfolio of cryptocurrencies with the lowest (highest) maximum daily return over the previous month. Table presents the value-weighted (VW) average weekly returns. The bottom two rows report the differences in weekly returns and the differences in three-factor alphas between portfolios 10 and 1, and the corresponding t-statistics. Newey-West (1987) adjusted t-statistics are presented in parentheses

$* * *$, ** and ${ }^{*}$ denote significance at $1 \%, 5 \%$ and $10 \%$, respectively

TSKEW is the measure for the third moment of returns and calculated as described in Eq. (10).

$$
\operatorname{TSKEW}_{i, t}=\frac{1}{D} \sum_{t=1}^{D}\left(\frac{R_{i, d}-\mu_{i}}{\sigma_{i}}\right)^{3}
$$

where $\mathrm{D}_{t}$ is the number of trading days in month $t, \mathrm{R}_{i, d}$ is the return on cryptocurrency $i$ on day $d, \mu_{i}$ is the average of returns on cryptocurrency $i$ in month $t$, and $\sigma_{i}$ is the standard deviation of returns on cryptocurrency $i$ in month $t$. We compute ISKEW after Boyer et al. (2010) as described in Eq. (11).

$$
\mathrm{R}_{i, d}-r_{f, d}=\alpha_{i}+\beta_{i}\left(R_{m, d}-r_{f, d}\right)+\theta_{i}\left(R_{m, d}-r_{f, d}\right)^{2}+\epsilon_{i, d}
$$

where as usual $\mathrm{R}_{i, d}$ is the return on cryptocurrency $i$ on day $d, \mathrm{R}_{m, d}$ is the cryptocurrency market portfolio return on day $d, \mathrm{r}_{f, d}$ is the risk-free rate on day $d$, and $\epsilon_{i, d}$ is the idiosyncratic return on day $d$. The idiosyncratic skewness (ISKEW) of cryptocurrency $i$ in month $t$ equals the skewness of daily residuals $\epsilon_{i, d}$ in month $t$.

Initially, we conduct the bivariate portfolio analysis where we first sort cryptocurrencies based on the skewness measure and then rank each of these deciles by MAX. Table 12 presents the results of the analysis. The first (second) column of Table 12 reports that, after controlling for TSKEW (ISKEW), the value-weighted mean return difference between high MAX and low MAX deciles is 2.95\% (2.65\%) with a NeweyWest adjusted t-stat of 8.06 (7.38). For TSKEW (ISKEW), the three-factor alpha difference is $2.67 \%(2.37 \%)$ with a $t$-stat of $6.41(6.10)$. The high degree of positive significance in return and alpha differences indicate that neither total skewness nor 
Table 13 Cross-sectional predictability of skewness

\begin{tabular}{lllllllll}
\hline TSKEW & ISKEW & BETA & SIZE & PRICE & MOM & REV & ILLIQ & R $^{2}(\%)$ \\
\hline 0.757 & & & & & & & & 50.25 \\
$(51.531)^{* * *}$ & & & & & & & & \\
0.588 & & -1.611 & 0.108 & -0.131 & 1.369 & 0.068 & 23.819 & 62.35 \\
$(5.046)^{* * *}$ & & $(-0.876)$ & $(0.910)$ & $(-0.964)$ & $(1.110)$ & $(0.231)$ & $(1.529)$ & \\
& 0.744 & & & & & & & 43.57 \\
& $(49.266)^{* * *}$ & & & & & & & \\
& 0.666 & 0.075 & -0.001 & -0.005 & 0.042 & -1.643 & -14.620 & 56.82 \\
& $(13.213)^{* * *}$ & $(0.158)$ & $(-0.044)$ & $(-0.128)$ & $(0.135)$ & $(-0.942)$ & $(-0.780)$ & \\
\hline
\end{tabular}

Each week from January 2014 to September 2020, we conduct a cryptocurrency-level cross-sectional regression of the skewness measures on lagged explanatory variables, including total skewness (TSKEW) and idiosyncratic skewness (ISKEW) as well as six other control variables - BETA, SIZE, PRICE, MOM, REV and ILLIQ. TSKEW refers to the total skewness measured for past month using daily returns. ISKEW is the skewness of regression residuals. BETA is the market beta calculated as the sum of coefficients on lag, current and lead returns on market portfolio. SIZE equals the natural logarithm of the cryptocurrency's market capitalization by the end of previous week. PRICE is the natural logarithm of one plus the cryptocurrency's price. MOM stands for momentum that equals the cumulative return over the previous three weeks skipping past week. REV stands for short-term reversal and equals the return in the past week. ILLIQ refers to Amihud illiquidity measure, which is calculated by the ratio of absolute daily cryptocurrency return to its mean dollar trading volume. Both dependent and independent variables are winsorized at $5 \%$ level from upper and lower tails. Table reports the time-series averages of the cross-sectional regression coefficients and corresponding t-statistics. Newey-West (1987) adjusted $t$-statistics are presented in parentheses

***, ** and ${ }^{*}$ denote significance at $1 \%, 5 \%$ and $10 \%$, respectively

Table 14 Cross-sectional return regressions with MAX and skewness

\begin{tabular}{|c|c|c|c|c|c|c|c|c|c|}
\hline MAX & BETA & SIZE & PRICE & MOM & REV & ILLIQ & TSKEW & ISKEW & E(TSKEW) \\
\hline & & & & & & & 0.009 & & \\
\hline & & & & & & & $(2.004)^{* *}$ & & \\
\hline & & & & & & & & 0.008 & \\
\hline & & & & & & & & $(1.874)^{*}$ & \\
\hline 0.424 & 0.064 & -0.003 & 0.005 & 0.035 & 0.031 & 1.612 & -0.006 & & \\
\hline$(7.298)^{* * * *}$ & $(1.710)^{*}$ & $(-1.226)$ & $(1.160)$ & $(1.841)^{*}$ & $(2.696)^{* * *}$ & $(0.186)$ & $(-0.635)$ & & \\
\hline 0.452 & 0.049 & -0.002 & 0.003 & 0.089 & 0.071 & -0.729 & & -0.009 & \\
\hline \multirow[t]{3}{*}{$(6.069)^{* * *}$} & $(1.249)$ & $(-0.716)$ & $(0.802)$ & $(1.978)^{* *}$ & $(2.552)^{* * *}$ & $(-0.265)$ & & $(-0.894)$ & \\
\hline & & & & & & & & & 0.038 \\
\hline & & & & & & & & & $(1.747)^{*}$ \\
\hline 0.411 & 0.053 & -0.004 & 0.009 & 0.026 & 0.025 & 1.145 & & & 0.031 \\
\hline$(6.973)^{* * *}$ & $(1.265)$ & $(-1.410)$ & $(1.586)$ & $(2.587)^{* * *}$ & $(2.650)^{* * *}$ & $(0.850)$ & & & (1.375) \\
\hline
\end{tabular}

Each week from January 2014 to September 2020, we conduct a cryptocurrency-level cross-sectional regression of the return in that week on lagged explanatory variables, which are lagged TSKEW, ISKEW, E(TSKEW), and MAX as well as six other control variables - BETA, SIZE, PRICE, MOM, REV and ILLIQ. TSKEW refers to the total skewness measured for past month using daily returns. ISKEW is the skewness of regression residuals. E(TSKEW) refers to the expected total skewness fitted each week throughout the cross-sectional regressions. MAX refers to the maximum daily return within a month. BETA is the market beta calculated as the sum of coefficients on lag, current and lead returns on market portfolio. SIZE equals the natural logarithm of the cryptocurrency's market capitalization by the end of previous week. PRICE is the natural logarithm of one plus the cryptocurrency's price. MOM stands for momentum that equals the cumulative return over the previous three weeks skipping past week. REV stands for short-term reversal and equals the return in the past week. ILLIQ refers to Amihud illiquidity measure, which is calculated by the ratio of absolute daily cryptocurrency return to its mean dollar trading volume. Both dependent and independent variables are winsorized at 5\% level from upper and lower tails. Table reports the time-series averages of the cross-sectional regression coefficients and corresponding t-statistics. Newey-West (1987) adjusted t-statistics are presented in parentheses

***, ** and * denote significance at $1 \%, 5 \%$ and $10 \%$, respectively

idiosyncratic skewness explains the link between extreme positive returns and future returns.

Boyer et al. (2010) state that among other characteristics, lagged skewness might be a weak predictor for future skewness, which we wish to consider. Therefore, we 
perform coin-level cross-sectional regressions of TSKEW and ISKEW on lagged values of skewness and six other control variables. Rules on winsorization still apply. The results are shown in Table 13. The univariate and multivariate regressions of both TSKEW and ISKEW indicate that skewness is extremely significant to predict subsequent skewness. Nevertheless, in our next analysis, we additionally consider expected total skewness $(E($ TSKEW $))$ as a control variable that is fitted each week throughout the cross-sectional regressions. Table 14 reports the coefficients and corresponding Newey-West adjusted t-statistics from cross-sectional regressions of subsequent weekly returns on MAX and nine other control variables, including TSKEW, ISKEW, E(TSKEW).

The time-series average coefficients of extreme positive returns are all statistically and economically significant in all the specifications. In univariate regressions, coefficients of skewness measures (TSKEW, ISKEW and E(TSKEW)) are all positive and statistically significant. TSKEW is significant at $5 \%$, and ISKEW and $E$ (TSKEW) are significant at $10 \%$ levels. However, in the full specifications, each of these variables are statistically insignificant. Consequently, the empirically indicated positive skewness is consistent with the findings of Wei (2018). Nevertheless, contrary to the findings of Jia et al. (2020), the results show that the skewness remains insignificant to predict subsequent returns. In addition, extreme positive return impact is significantly persistent and robust to controls for skewness measures.

\section{Extreme positive returns and investor sentiment}

The empirical literature documents that a significant relationship exists between the investor sentiment and expected stock returns (Baker and Wurgler 2007; Yang and Zhou 2015; He et al. 2019). Baker and Wurgler (2006) present lower subsequent returns, and Stambaugh et al. (2012) report common mispricing in stocks during high sentiment periods. When investors are optimistic about the subsequent returns, they might be inclined to invest in stocks with lottery-like features. This gambling tendency originates from the expectation of high-performing stocks to continue winning in the future. However, as in the theoretical model of Brunnermeier and Gollier (2007), overoptimism might result in underperforming stock investments. While Bali et al. (2011) explains this phenomenon by MAX effect, Fong and Toh (2014) indicate the dependency of MAX effect on investor sentiment. Next, if the MAX effect is induced by investor optimism, the significance will vanish when we control for the cryptocurrency market sentiment. Hence, the aim of this section is to understand the relationship between the investor sentiment and extreme positive returns.

We perform the univariate portfolio analysis to test the effect of investor sentiment on subsequent returns. We define two periods: low sentiment and high sentiment. As a proxy for market sentiment, we use Bitcoin Sentiment Index, which is constructed with regards to the Bitcoin conversations collected from Twitter, Reddit, and Bitcointalk. The value changes between 0 and 1 , where 0 refers to extreme bearish and 1 refers to extreme bullish. ${ }^{17}$ We categorize weekly data into bins of low sentiment whenever the sentiment

${ }^{17}$ Further information is available at https://www.augmento.ai/bitcoin-sentiment/. 
Table 15 Returns on portfolios of cryptocurrencies sorted by MAX after controlling for investor sentiment

\begin{tabular}{lll}
\hline Decile & Low sentiment & High sentiment \\
\hline Low MAX & 0.010 & 0.008 \\
2 & 0.021 & 0.021 \\
3 & 0.013 & 0.018 \\
4 & 0.021 & 0.011 \\
5 & 0.015 & 0.035 \\
6 & 0.011 & 0.028 \\
7 & 0.027 & 0.011 \\
8 & 0.029 & 0.040 \\
9 & 0.023 & 0.030 \\
High MAX & 0.038 & 0.041 \\
Return difference & 0.028 & 0.033 \\
Alpha difference & $(3.157)^{* * *}$ & $(1.979)^{* *}$ \\
& 0.025 & 0.030 \\
\hline
\end{tabular}

Decile portfolios are formed every week from January 2014 to September 2020 by ranking cryptocurrencies based on the maximum daily return (MAX) within the past month. Decile 1 (10) is the portfolio of cryptocurrencies with the lowest (highest) maximum daily return over the previous month. Table presents the value-weighted (VW) average weekly returns on low sentiment and high sentiment bins. The bottom two rows report the differences in weekly returns and the differences in alphas between portfolios 10 and 1, and the corresponding t-statistics. Newey-West (1987) adjusted $\mathrm{t}$-statistics are presented in parentheses

$* * *, * *$ and $*$ denote significance at $1 \%, 5 \%$ and $10 \%$, respectively

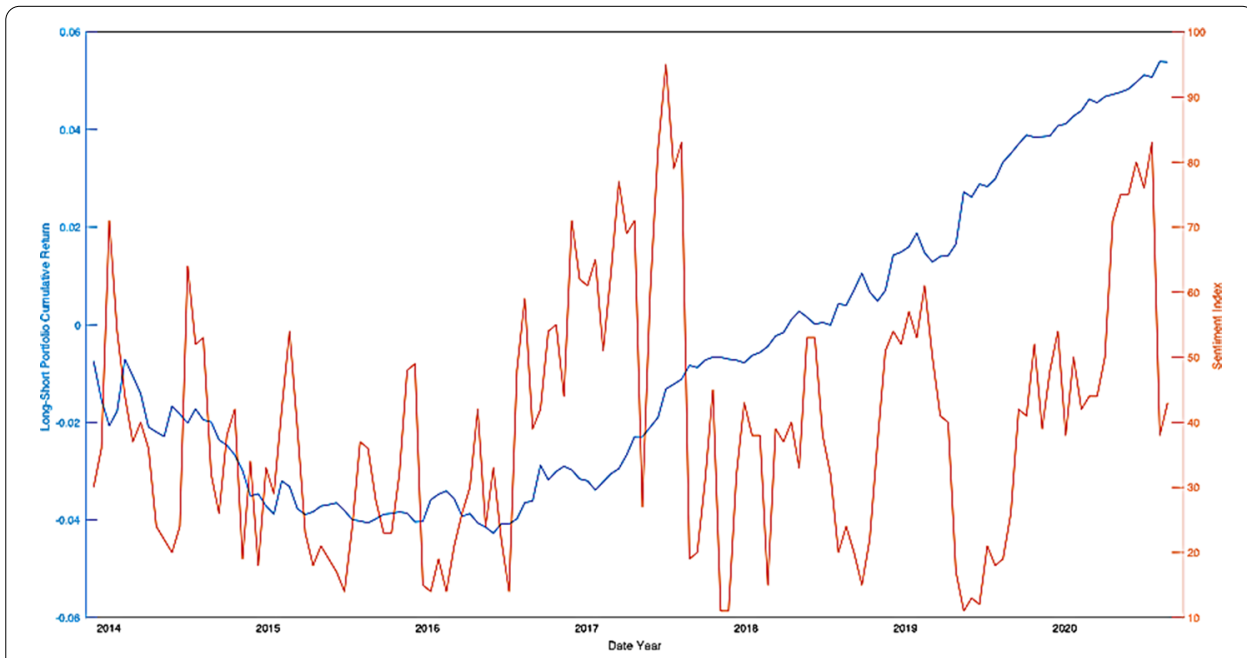

Fig. 1 Long-short portfolio cumulative return and sentiment index

index is below the sample median value and high sentiment whenever the sentiment index is above the sample median value. We report the value-weighted average raw return and three-factor alpha differences in Table 15, with the corresponding t-statistics. For low (high) sentiment periods, the mean return difference between decile 10 (high MAX) and decile 1 (low MAX) is $2.80 \%$ (3.25\%) with an adjusted t-stat of 3.16 (1.98). These magnitudes are very similar with those reported in Table 2, which supports the significance of extreme positive returns to explain subsequent returns. The results are consistent with the positive MAX effect reported in our analyses. Fong and Toh (2014) claim that the high investor sentiment periods drive the MAX effect in stock markets; 
however, we report similar magnitudes and significance levels in both states. This indicates investor preference over lottery-like assets both following low and high sentiment periods for the cryptocurrency market, contrary to the findings of Fong and Toh (2014) in the stock market.

Furthermore, we perform long-short portfolio analysis with regards to the low MAX and high MAX decile performances. We calculate the subsequent long-short portfolio returns (high MAX decile - low MAX decile) to control whether MAX effect is driven by low or high sentiment periods. We plot the time-series of cumulative return performance and sentiment index in Fig. $1 .^{18}$ The figure supports the findings in Table 15 that the performance of long-short hedge portfolio based on MAX is slightly higher following high sentiment states. In addition, the cumulative return of the long-short portfolio decreases in the early sample period before moving upwards until the end. This might be interpreted as the investors acting pessimistic and taking short position whenever the sentiment index is at low levels in the beginning. Immediately after the sentiment index begins to increase, the investors in the cryptocurrency market embrace an optimistic behavior and take a long position until the end of the sample period. Nevertheless, the MAX effect is statistically significant for both high and low sentiment periods, indicating that MAX effect is also robust after controlling for investor sentiment.

\section{Conclusion}

Investor preference for lottery-like assets is a novel phenomenon for the cryptocurrency market. Within this context, we follow Bali et al. (2011) and investigate the impact of the maximum daily return within the past month (MAX effect) on next week returns for the period from January 2014 to September 2020. The univariate and bivariate portfolio analyses show that MAX effect is present and persistent in the cryptocurrency market. The positive impact of extreme positive returns remains statistically significant when we use the averages of $N(N=2,3,4$, and 5$)$ highest daily returns within the previous month. In addition to the lottery-like features of stocks documented in the literature, weekly regression analyses provide strong evidence that a significant positive relation exists between extreme positive returns and expected returns in the cryptocurrency market. We further show that these results are robust after controlling for size, price, momentum, short-term reversal, and liquidity.

Moreover, we analyze the possibility of extreme positive returns acting as a substitute for either volatility or skewness. To check this, we utilize different measures for volatility and skewness and report that the explanatory power of extreme positive returns over subsequent returns continues to exist. Finally, to understand the link between extreme positive returns and investor sentiment, we categorize our data into bins of low sentiment and high sentiment, and we conduct portfolio analysis. Additionally, we investigate the time series of the long-short portfolio return to check whether cycles exist, and we control whether investor sentiment is persistent. We report that the MAX effect is

\footnotetext{
18 The reason that we consider the long-short portfolio return along with the sentiment analysis is to understand whether cycles exist within our sample period following the sentiment index. Therefore, we perform autocorrelation tests for the sentiment index to analyze whether sentiment is persistent. The results of both Durbin Watson Test and Ljung-Box Q Test show that there is no evidence of residuals of sentiment returns being positively correlated. The results are available upon request.
} 
also robust to controls for investor sentiment. Our results signal lack of efficiency in the cryptocurrency market by which, investors might gain an advantage while forming their portfolios. It would be prudent for market participants and fund managers to consider the effect of extreme positive returns. However, further research is necessary to make interpretations and exploit this potentially fruitful anomaly.

\author{
Acknowledgements \\ There are no acknowledgements to declare.
}

\title{
Authors' contributions
}

All authors have contributed equally to this research article. The authors read and approved the final manuscript.

\section{Funding}

Funding was provided by türkiye bilimler akademisi (Grant Outstanding Young Scientist).

Availability of data and materials

Data and materials are available upon request from the corresponding author.

\section{Declarations}

\section{Competing interests}

The authors declare that they have no competing interests.

Received: 7 January 2021 Accepted: 24 August 2021

Published online: 08 September 2021

\section{References}

Akhtaruzzaman M, Sensoy A, Corbet S (2020) The influence of Bitcoin on portfolio diversification and design. Finance Res Lett $37: 101344$

Akyildirim E, Corbet S, Lucey B, Sensoy A, Yarovaya L (2020) The relationship between implied volatility and cryptocurrency returns. Finance Res Lett 33:101212

Akyildirim E, Goncu A, Sensoy A (2021) Prediction of cryptocurrency returns using machine learning. Ann Oper Res 297:3-36 Al-Yahyaee KH, Mensi W, Yoon SM (2018) Efficiency, multifractality, and the long-memory property of the Bitcoin market: a comparative analysis with stock, currency, and gold markets. Finance Res Lett 27:228-234

Amihud Y (2002) Illiquidity and stock returns: cross-section and time-series effects. J Financ Mark 5:31-56

Ang A, Hodrick RJ, Xing Y, Zhang X (2006) The cross-section of volatility and expected returns. J Finance 61:259-299

Annaert J, De Ceuster M, Verstegen K (2013) Are extreme returns priced in the stock market? European evidence. J Bank Finance 37(9):3401-3411

Arditti F (1967) Risk and the required return on equity. J Finance 22:19-36

Baker M, Wurgler J (2006) Investor sentiment and the cross-section of stock returns. J Finance 61 (4):1645-1680

Baker M, Wurgler J (2007) Investor sentiment in the stock market. J Econ Perspect 21(2):129-151

Balcilar M, Bouri E, Gupta R, Roubaud D (2017) Can volume predict bitcoin returns and volatility? A quantiles-based approach. Econ Model 64:74-81

Bali TG, Cakici N (2008) Idiosyncratic volatility and the cross section of expected returns. J Financ Quant Anal 43:29-58

Bali TG, Cakici N, Whitelaw RF (2011) Maxing out: stocks as lotteries and the cross-section of expected returns. J Financ Econ 99(2):427-446

Barberis N, Huang M (2008) Stocks as lotteries: the implications of probability weighting for security prices. Am Econ Rev 98(5):2066-2100

Barinov A (2018) Stocks with extreme past returns: lotteries or insurance? J Financ Econ 129(3):458-478

Berggrun L, Cardona E, Lizarzaburu E (2019) Extreme daily returns and the cross-section of expected returns: evidence from Brazil. J Bus Res 102:201-211

Boyer B, Mitton T, Vorkink K (2010) Expected idiosyncratic skewness. Rev Financ Stud 23(1):169-202

Brunnermeier MK, Gollier C (2007) Optimal beliefs, asset prices, and the preference for skewed returns. Am Econ Rev 97(2):159-165

Caporale GM, Gil-Alana L, Plastun A (2018) Persistence in the cryptocurrency market. Res Int Bus Financ 46:141-148

Carhart MM (1997) On persistence in mutual fund performance. J Finance 52:57-82

Chan LKC, Hamao Y, Lakonishok J (1991) Fundamentals and stock returns in Japan. J Finance 46(5):1739-1764

Chan YC, Chui AC (2016) Gambling in the Hong Kong stock market. Int Rev Econ Finance 44:204-218

Chen CYH, Hafner CM (2019) Sentiment-induced bubbles in the cryptocurrency market. J Risk Financ Manag 12:53

Conrad J, Dittmar RF, Ghysels E (2013) Ex-ante skewness and expected stock returns. J Finance 68:85-124

Corbet S, Lucey B, Urquhart A, Yarovaya L (2019) Cryptocurrencies as a financial asset: a systematic analysis. Int Rev Financ Anal 62:182-199

Corbet S, Lucey B, Yarovaya L (2018a) Datestamping the bitcoin and ethereum bubbles. Financ Res Lett 26:81-88

Corbet S, Meegan A, Larkin C, Lucey B, Yarovaya L (2018b) Exploring the dynamic relationships between cryptocurrencies and other financial assets. Econ Lett 165:28-34

Da Z, Engelberg J, Gao P (2015) The sum of all FEARS investor sentiment and asset prices. Rev Financ Stud 28(1):1-32 
Dimson E (1979) Risk measurement when shares are subject to infrequent trading. J Financ Econ 7:197-226

Dyhrberg AH (2016) Bitcoin, gold and the dollar-a GARCH volatility analysis. Financ Res Lett 16:85-92

Eross A, McGroarty F, Urquhart A, Wolfe S (2019) The intraday dynamics of Bitcoin. Res Int Bus Financ 49:71-81

Fama EF, French KR (1992) The cross-section of expected returns. J Finance 47(2):427-465

Fama EF, French KR (1993) Common risk factors in the returns on stocks and bonds. J Financ Econ 33:3-56

Fama EF, MacBeth JD (1973) Risk, return, and equilibrium: empirical tests. J Polit Econ 81(3):607-636

Fong WM, Toh B (2014) Investor sentiment and the MAX effect. J Bank Finance 46:190-201

Fu F (2009) Idiosyncratic risk and the cross-section of expected stock returns. J Financ Econ 91:24-37

Garman MB, Klass MJ (1980) On the estimation of security price volatilities from historical data. J Bus 53(1):67-78

Grobys K, Junttila J (2021) Speculation and lottery-like demand in cryptocurrency markets. J Int Financ Mark Inst Money 71:101289

Grobys K, Sapkota N (2019) Cryptocurrencies and momentum. Econ Lett 180:6-10

Harvey CR, Siddique A (2000) Conditional skewness in asset pricing tests. J Finance 55:1263-1295

He Z, He L, Wen F (2019) Risk compensation and market returns: the role of investor sentiment in the stock market. Emerg Mark Financ Trade 55(3):704-718

Hong K (2017) Bitcoin as an alternative investment vehicle. Inf Technol Manag 18:265-275

Hung W, Yang JJ (2018) The MAX effect: lottery stocks with price limits and limits to arbitrage. J Financ Markets 41:77-91

Jegadeesh N, Titman S (1993) Returns to buying winners and selling losers: implications for stock market efficiency. J Finance 48(1):65-91

Jia Y, Liua Y, Yan S (2020) Higher moments, extreme returns, and cross-section of cryptocurrency returns. Finance Res Lett 101536

Kaitazi A, Moro A (2019) The role of bitcoin in well diversified portfolios: a comparative global study. Int Rev Financ Anal 61:143-157

Karalevicius V, Degrande N, De Weerdt J (2018) Using sentiment analysis to predict interday bitcoin price movements. J Risk Finance 19(1):56-75

Katsiampa P, Corbet S, Lucey B (2019) Volatility spillover effects in leading cryptocurrencies: a BEKK-MGARCH analysis. Financ Res Lett 29:68-74

Kou G, Akdeniz O, Dincer H, Yuksel S (2021a) Fintech investments in European banks: a hybrid IT2 fuzzy multidimensional decision-making approach. Financ Innov 7:39

Kou G, Xu Y, Peng Y, Shen F, Chen Y, Chang K, Kou S (2021 b) Bankruptcy prediction for SMEs using transactional data and twostage multiobjective feature selection. Decis Support Syst 140:113429

Kraus A, Litzenberger RH (1976) Skewness preference and the valuation of risky assets. J Finance 31:1085-1100

Kumar A (2009) Who gambles in the stock market? J Finance 64:1889-1933

LiY, Urquhart A, Wang P, Zhang W (2020a)Max momentum in cryptocurrency markets. Available at SSRN

Li Y, Zhang W, Xiong X, Wang P (2020b) Does size matter in the cryptocurrency market? Appl Econ Lett 27(14):1141-1149

Liu W, Liang X, Cui G (2020) Common risk factors in cryptocurrency. Econ Model 86:299-305

Liu Y, Tsyvinski A (2018) Risks and returns of cryptocurrency. NBER working paper no. 24877. (24877)

Liu Y, Tsyvinski A, Wu X (2019) Common risk factors in cryptocurrency. NBER working paper no. 25882. (25882)

Makarov I, Schoar A (2020) Trading and arbitrage in cryptocurrency markets. J Financ Econ 135(2):293-319

Mensi W, Lee YJ, Al-Yahyaee KH, Sensoy A, Yoon SM (2019) Intraday downward/upward multifractality and long memory in Bitcoin and Ethereum markets: an asymmetric multifractal detrended fluctuation analysis. Res Int Bus Financ 31:19-25

Mitton T, Vorkink K (2007) Equilibrium underdiversification and the preference for skewness. Rev Financ Stud 20(4):1255-1288

Nakamoto S (2008) Bitcoin: a peer-to-peer electronic cash system. https://bitcoin.org/bitcoin.pdf

Nartea GV, Kong D, Wu J (2017) Do extreme returns matter in emerging markets? Evidence from the Chinese stock market. J Bank Finance 76:189-197

Newey WK, West KD (1987) A simple, positive, semi-definite, heteroskedasticity and autocorrelation consistent covariance matrix. Econometrica 55:703-708

Polasik M, Piotrowska Al, Wisniewski TP, Kotkowski R, Lightfoot G (2015) Price fluctuations and the use of Bitcoin: an empirical inquiry. Int J Electron Commer 20(1):9-49

Scholes M, Williams J (1977) Estimating betas from nonsynchronous data. J Financ Econ 5:309-327

Scott RC, Horvath PA (1980) On the direction of preference for moments of higher order than the variance. J Finance 35:915-919

Sensoy A (2019) The inefficiency of bitcoin revisited: a high-frequency analysis with alternative currencies. Financ Res Lett 28:68-73

Shen D, Urquhart A, Wang P (2020) Forecasting the volatility of Bitcoin: the importance of jumps and structural breaks. Eur Financ Manag 26:1294-1323

Smith DR (2007) Conditional coskewness and asset pricing. J Empir Financ 14:91-119

Stambaugh RF, Yu J, Yuan Y (2012) The short of it: investor sentiment and anomalies. J Financ Econ 104:288-302

Tzouvanas P, Kizys R, Tsend-Ayush B (2019) Momentum trading in cryptocurrencies: short-term returns and diversification benefits. Econ Lett 191:108728

Urquhart A (2017) Price clustering in Bitcoin. Econ Lett 159:145-148

Urquhart A, Zhang H (2019) Is Bitcoin a hedge or safe haven for currencies? An intraday analysis. Int Rev Financ Anal 63:49-57

Vidal-Tomas D, Ibanez A (2018) Semi-strong efficiency of Bitcoin. Financ Res Lett 27:259-265

Walkshäusl C (2014) The MAX effect: European evidence. J Bank Finance 42:1-10

Wei WC (2018) Liquidity and market efficiency in cryptocurrencies. Econ Lett 168:21-24

Yang C, Zhou L (2015) Investor trading behavior, investor sentiment and asset prices. N Am J Econ Finance 34:42-62

Zha Q, Kou G, Zhang H, Liang H, Chen X, Li C, Dong Y (2021) Opinion dynamics in finance and business: a literature review and research opportunities. Financ Innov 6:44 
Zhang W, LiY (2020) Is idiosyncratic volatility priced in cryptocurrency markets? Res Int Bus Finance 54:101252

Zhang W, Wang P, Li X, Shen D (2018) The inefficiency of cryptocurrency and its cross-correlation with Dow Jones Industrial Average. Physica A 510:658-670

Zhong A, Gray P (2016) The MAX effect: an exploration of risk and mispricing explanations. J Bank Finance 65:76-90

Zhu Z, Harrison DM, Seiler MJ (2020) Preference for lottery features in real estate investment trusts. Int Rev Econ Finance 69:599-613

\section{Publisher's note}

Springer Nature remains neutral with regard to jurisdictional claims in published maps and institutional affiliations.

Submit your manuscript to a SpringerOpen ${ }^{\circ}$ journal and benefit from:

- Convenient online submission

- Rigorous peer review

- Open access: articles freely available online

- High visibility within the field

- Retaining the copyright to your article

Submit your next manuscript at $\boldsymbol{\Delta}$ springeropen.com 